\title{
Carbon dioxide photoreduction in prebiotic environments
}

\author{
Dhanalakshmi Vadivel $^{1,2} \cdot$ Francesco Ferraro $^{1} \cdot$ Daniele Merli ${ }^{2,3} \cdot$ Daniele Dondi $^{1,2}$
}

Received: 2 November 2021 / Accepted: 27 December 2021 / Published online: 2 February 2022

(c) The Author(s) 2022

\begin{abstract}
The reduction of carbon dioxide is one of the hottest topics due to the concern of global warming. Carbon dioxide reduction is also an essential step for life's origins as photoautotrophs arose soon after Earth formation. Both the topics are of high general interest, and possibly, there could be a fruitful cross-fertilization of the two fields. Herein, we selected and collected papers related to photoreduction of carbon dioxide using compounds easily available on the Earth and considered of prebiotic relevance. This work might be useful also to scientists interested in carbon dioxide photoreduction and/or to have an overview of the techniques available.
\end{abstract}

Keywords Prebiotic photochemistry $\cdot$ Carbon dioxide fixation $\cdot$ Prebiotic photosynthesis $\cdot$ Heavy metal-free carbon dioxide photoreduction · Prebiotic photoautotrophs · Origins of life

\section{Introduction}

Carbon dioxide photoreduction is one of the most important research fields nowadays, especially due the actual global concern on increasing greenhouse effect. In fact, very recently [1], scientists claimed to have successfully converted carbon dioxide to starch with a higher efficiency with respect to starch photosynthesis in maize.

In recent years, photochemical molecular devices were developed to fix $\mathrm{CO}_{2}$ by photochemical reaction [2-7]. In most of the reduction reactions which occur in multielectron mode, as an electron reservoir at the photocatalytic surface (i.e., noble metals) greatly enhances the yields of conversion.

In this review, we will take into account photoreduction studies that use simple compounds easily available, plausible even in a prebiotic environment. The listed methods could be useful not only to scientists working on prebiotic chemistry,

Dhanalakshmi Vadivel

dhanalakshmi.vadivel@unipv.it

1 Department of Chemistry, Section of General Chemistry, University of Pavia, 27100 Viale Taramelli 12, Pavia, Italy

2 INFN, Sezione di Pavia, Via Agostino Bassi, 6 - 27100 Pavia, Italy

3 Department of Chemistry, Section of Analytical Chemistry, University of Pavia, 27100 Viale Taramelli 12, Pavia, Italy but also for the development of carbon dioxide photoreduction using simple or readily available compounds.

Plausible prebiotic photocatalysts might be minerals naturally occurring in the primordial Earth, together with compounds found in interstellar space (and other celestial bodies) or chemicals synthesized on the Earth in specific places (geothermal vents and volcanic eruptions) or due to the action of energy (lighting and solar light) on simple organic compounds. Also, more complex organic compounds such as porphyrins or other metal complexes (with easily available metals) produced in straightforward synthesis from simple organic compounds will be considered in this work.

Carbon dioxide reduction can lead to different $\mathrm{C} 1 \mathrm{com}$ pounds and intermediates, depending on the number of electrons used in the reduction. Obviously, the transfer of a single electron at a time is easy from the practical point of view, but the single electron reduction of carbon dioxide leads to the unstable radical anion intermediate and requires very high potentials. Even so, the free energy value for the reduction corresponds to a photon in the visible-light spectrum, showing that photochemistry can play a significant role. Figure 1 shows the free energies for the reduction of carbon dioxide to the most common $\mathrm{C} 1$ compounds; values are calculated starting from the electrochemical reduction potentials at $\mathrm{pH}=7[8,9]$.

As it is illustrated in Fig. 1, all the reactions are unfavorable from the free energy point of view. The reduction value, however, depends on the $\mathrm{pH}$, presence/absence of 


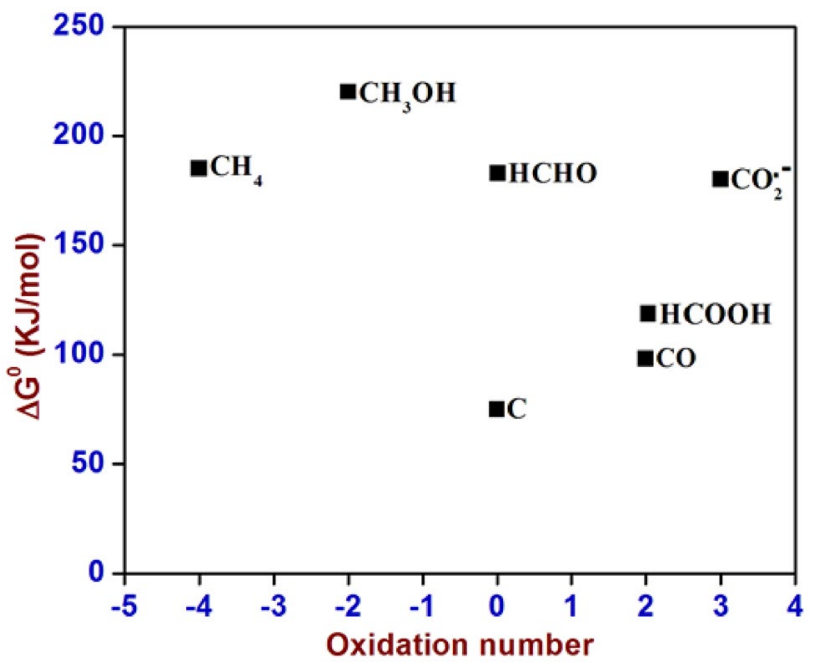

Fig. 1 Calculated $\Delta \mathrm{G}$ of reaction obtained from the electrochemical reduction potentials of $\mathrm{CO}_{2}$ to $\mathrm{Cl}$ compounds in water at $\mathrm{pH}=7$ vs. NHE

water and other parameters. Less unfavorable are the reduction of carbon dioxide with hydrogen [10] as shown in the reactions below, where the last two reactions (conversion of $\mathrm{CO}_{2}$ to methanol and methane) are even thermodynamically favorable

$$
\begin{aligned}
& \mathrm{H}_{2(\mathrm{~g})}+\mathrm{CO}_{2(\mathrm{~g})} \rightarrow \mathrm{CO}_{(\mathrm{g})}+\mathrm{H}_{2} \mathrm{O}_{(\mathrm{l})} \Delta \mathrm{G}=20 \mathrm{~kJ} / \mathrm{mol} \\
& \mathrm{H}_{2(\mathrm{~g})}+\mathrm{CO}_{2(\mathrm{~g})} \rightarrow \mathrm{HCOOH}_{(\mathrm{l})} \Delta \mathrm{G}=33 \mathrm{~kJ} / \mathrm{mol} \\
& 2 \mathrm{H}_{2(\mathrm{~g})}+\mathrm{CO}_{2(\mathrm{~g})} \rightarrow \mathrm{HCHO}_{(\mathrm{g})}+\mathrm{H}_{2} \mathrm{O}_{(\mathrm{l})} \Delta \mathrm{G}=44 \mathrm{~kJ} / \mathrm{mol} \\
& 3 \mathrm{H}_{2(\mathrm{~g})}+\mathrm{CO}_{2(\mathrm{~g})} \rightarrow \mathrm{CH}_{3} \mathrm{OH}_{(\mathrm{l})}+\mathrm{H}_{2} \mathrm{O}_{(\mathrm{l})} \Delta \mathrm{G} \\
& =-9.2 \mathrm{~kJ} / \mathrm{mol} \\
& 4 \mathrm{H}_{2(\mathrm{~g})}+\mathrm{CO}_{2(\mathrm{~g})} \rightarrow \mathrm{CH}_{4(\mathrm{~g})}+2 \mathrm{H}_{2} \mathrm{O}_{(\mathrm{g})} \Delta \mathrm{G} \\
& =-114 \mathrm{~kJ} / \mathrm{mol}(\text { Sabatier reaction }) .
\end{aligned}
$$

A similar reaction is exploited by actual chemoautotrophic acetogenic bacteria [11] that could use carbon dioxide and hydrogen to sustain their metabolism and to produce biomass with a reaction that can be summarized as follows:

$$
\begin{aligned}
& 2 \mathrm{CO}_{2}+4 \mathrm{H}_{2}+\mathrm{nADP}+\mathrm{nP}_{\mathrm{i}} \rightarrow \\
& \mathrm{CH}_{3} \mathrm{COOH}+\mathrm{nATP}+(2+\mathrm{n}) \mathrm{H}_{2} \mathrm{O} .
\end{aligned}
$$

Hydrogen on Earth is not implausible at low levels. In fact, hydrogen can be generated by geochemical processes $[12,13]$, together with reduced hydrocarbons such as methane, that can be produced thanks to the reaction [14]

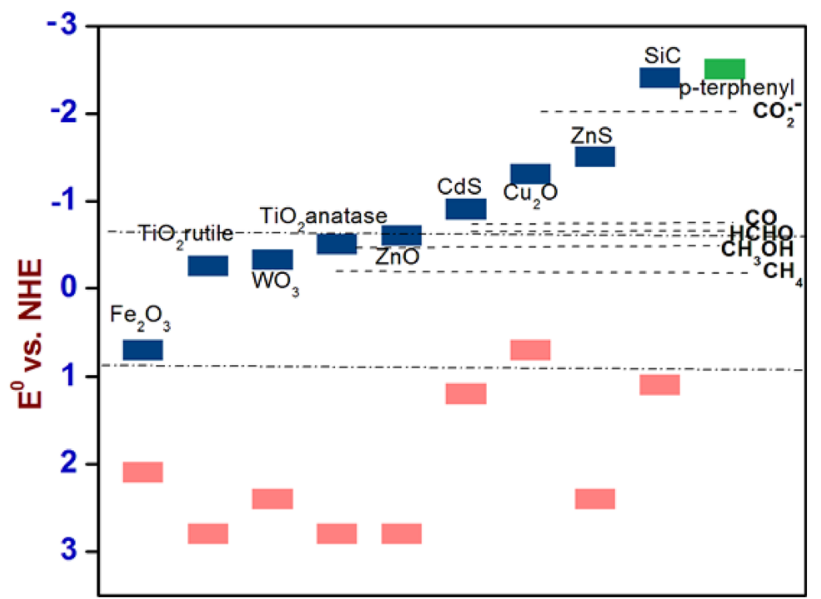

Fig. 2 Electrochemical reduction potentials at $\mathrm{pH}=7$ vs. NHE for some common semiconductors (blue rectangles are the conduction bands while the pink rectangles are the valence bands). In green, the potential of p-terphenyl (excited state). Dashed gray lines represent the carbon dioxide reduction potentials to the $\mathrm{C} 1$ compounds shown on the right. The two black dash-dotted lines represent the potential limits for reactions in water

$8 \mathrm{FeO}+\mathrm{CaCO}_{3}+2 \mathrm{H}_{2} \mathrm{O} \rightarrow 4 \mathrm{Fe}_{2} \mathrm{O}_{3}+\mathrm{CH}_{4}+\mathrm{CaO}$.

Other chemoautotrophs could use reduced nitrogen $\left(\mathrm{NH}_{4}{ }^{+}, \mathrm{NO}_{2}{ }^{-}\right)$, sulfur $\left(\mathrm{S}_{2} \mathrm{O}_{3}{ }^{2-}, \mathrm{H}_{2} \mathrm{~S}\right)$, metals $\left(\mathrm{Fe}^{2+}, \mathrm{Mn}^{2+}\right)$ or other reducing agents $\left(\mathrm{CO}, \mathrm{CH}_{4}, \mathrm{CH}_{3} \mathrm{OH}\right)$ to attain the carbon dioxide reduction [15]. Also native metals like $\mathrm{Fe}, \mathrm{Ni}$ and $\mathrm{Co}$ can promote the thermal reduction of $\mathrm{CO}_{2}$ to acetate and pyruvate $[16,17]$. Iron (II), in the presence of other simple organic compounds, is able to convert, under a mild hydrothermal environment, pyruvate and glyoxylate into 9 of the 11 intermediates of the Krebs cycle [18]. In another work, the Krebs cycle was run non-enzymatically with the help of FeS and sulfate radicals [19].

However, due to the Earth composition and structure, the free energy production of chemoautotrophs could take into account only a small fraction of the conversion of $\mathrm{CO}_{2}$ into organic matter [20]. Due to the intrinsic nature of photochemistry, sunlight is the designated source to have a durable ecosystem as it occurs nowadays.

Inorganic semiconductors could have a conductive band able to reduce carbon dioxide (Fig. 2) and some of them are also compatible with a prebiotic environment. Obviously, the presence of a sufficiently high redox potential is not a guarantee of high yields of conversion. In fact, many side reactions could lead to a decrease of their activity, such as chemical instability or fast recombination of photogenerated electron-hole pairs. Some organic molecules could also be active with photoinduced electron transfer, like in the case of p-terphenyl (Fig. 2) that is chosen as comparison [21, 22]. 
Scheme 1 Carbon dioxide incorporation into a photogenerated high energy intermediate

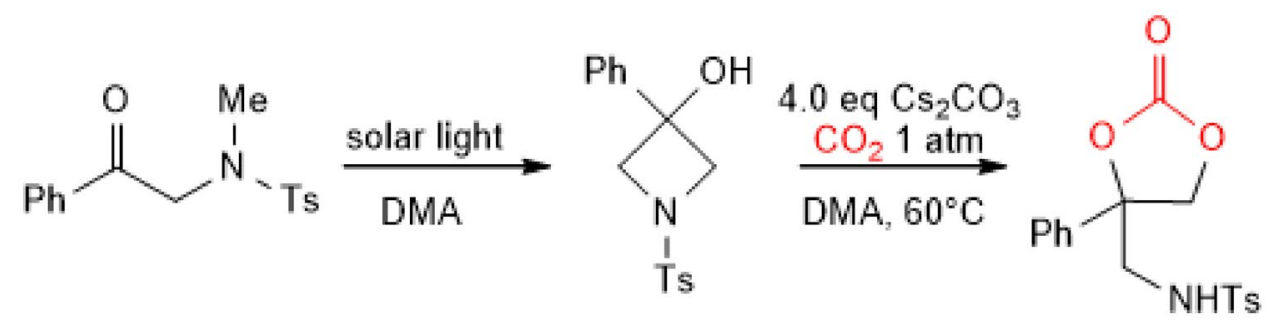

In the current review, articles are divided into sections and discussed toward their possible prebiotic significance.

\section{Metal-free organic compounds}

Amines are the easiest way to think about an interaction between the acidic carbon dioxide and an organic base. It is also known that ethanolamines and derivatives [23] possess a high affinity for carbon dioxide.

However, the adsorption/desorption does not change the chemical form of carbon dioxide. Different is the case if ethanolamine is linked to titania through solvothermal process [24], where photoconversion yields of $\mathrm{CO}_{2}$ to $\mathrm{CO}$ increases more than 50-fold with respect to neat $\mathrm{TiO}_{2}$.

Due to the scarce reactivity of $\mathrm{CO}_{2}$ and the unique property of photons, photochemical reactions could give rise to high energy intermediates, going uphill with respect to thermal reactions. This was exploited [25] to produce an azetidine cycle from solar light irradiation of an alpha aminoketone (see Scheme 1).

The azetidine intermediate reacts with carbon dioxide giving a cyclic carbonate. Even if this reaction is not immediately prebiotic, it could give some hints on the possible importance of unstable intermediates that might be formed from the irradiation of simple compounds.

Enamides can also be photoactivated by transforming them in anion intermediates through successive photoinduced electron transfer using 1,2,3,5-tetrakis(carbazol-9-yl)4,6-dicyano-benzene (4CzIPN) as photocatalyst, i-Pr ${ }_{2} \mathrm{NEt}$ as reductant, and $\mathrm{Cs}_{2} \mathrm{CO}_{3}$ as base [26]. The anion then reacts with carbon dioxide to give the corresponding carboxylic acid (Scheme 2).

Aromatic hydrocarbons are detected in meteorites, comets and interstellar space, and could be considered as pigments for light absorption and prebiotic photosynthesis [27].

Several carbon dioxide reactions with (photo) activated $\mathrm{C}(\mathrm{sp} 3)-\mathrm{H}$ hydrogen are described in the literature [28]. As an interesting example, benzylic hydrogen might undergo an intermolecular hydrogen photoabstraction from an aromatic ketone. This gives rise to a diradical [29] which subsequently rearranges to the o-quinodimethane intermediate that undergoes a $4+2$ addition with $\mathrm{CO}_{2}$ (Scheme 3$)$.
Carbon dioxide radical anion can be generated under photoinduced single electron transfer with p-terphenyl. With the latter photocatalyst, the reduction of $\mathrm{CO}_{2}$ to formic acid (with traces of $\mathrm{CO}$ ) was attained using triethylamine as a sacrificial donor [30] with a turnover number of 4. Starting from that idea, the unstable radical anion of carbon dioxide could be trapped to give adducts. An interesting case is the closure of the catalytic cycle with the reformation of p-terphenyl by the reaction of its radical cation with a tertiary amine. The latter is used, after the loss of a proton, to trap the incoming carbon dioxide radical anion and exploited for the preparation of alpha amino acids (Scheme 4) [31]. The reaction can be carried efficiently with a photochemical flow reactor.

\section{Ferrocyanide}

Ferrocyanide might be considered prebiotic and compatible with hydrogen cyanide chemistry related to nucleobase synthesis. Irradiation of ferrocyanide gives rise to a hydrated electron and the oxidation of the iron. This could lead subsequently to the formation of an insoluble precipitate of Prussian blue [32]. $\mathrm{CO}_{2}$ reduction in the aqueous medium by using ferrocyanide/ $\mathrm{TiO}_{2}$ gives rise to formic acid and formaldehyde as photoproducts in nitrogen atmosphere. The yield of formation of products is increased with increasing the concentration of ferrocyanide over $\mathrm{TiO}_{2}$. Nevertheless, an $n$ excessive concentration of ferrocyanide reverses its effect due to the formation of a multilayered ferrocyanide over $\mathrm{TiO}_{2}$ which poison the catalyst. The first product formed was formic acid and during the irradiation is converted into formaldehyde (IIustration 1).

The higher loading of ferrocyanide gave a higher yield of formaldehyde and formic acid as photo products in a shorter time. The lower loading of ferrocyanide gave instead the maximum yield of formic acid with longer exposure time. Also, the particle size affects the reaction yield: a higher amounts of photoproducts was obtained with smaller particles [33]. 
Scheme 2 Carbon dioxide incorporation via generation of anion produced by photoinduced electron transfer
Scheme 3 Carbon dioxide incorporation via photogeneration of o-quinodimethane and subsequent $4+2$ reaction with $\mathrm{CO}_{2}$

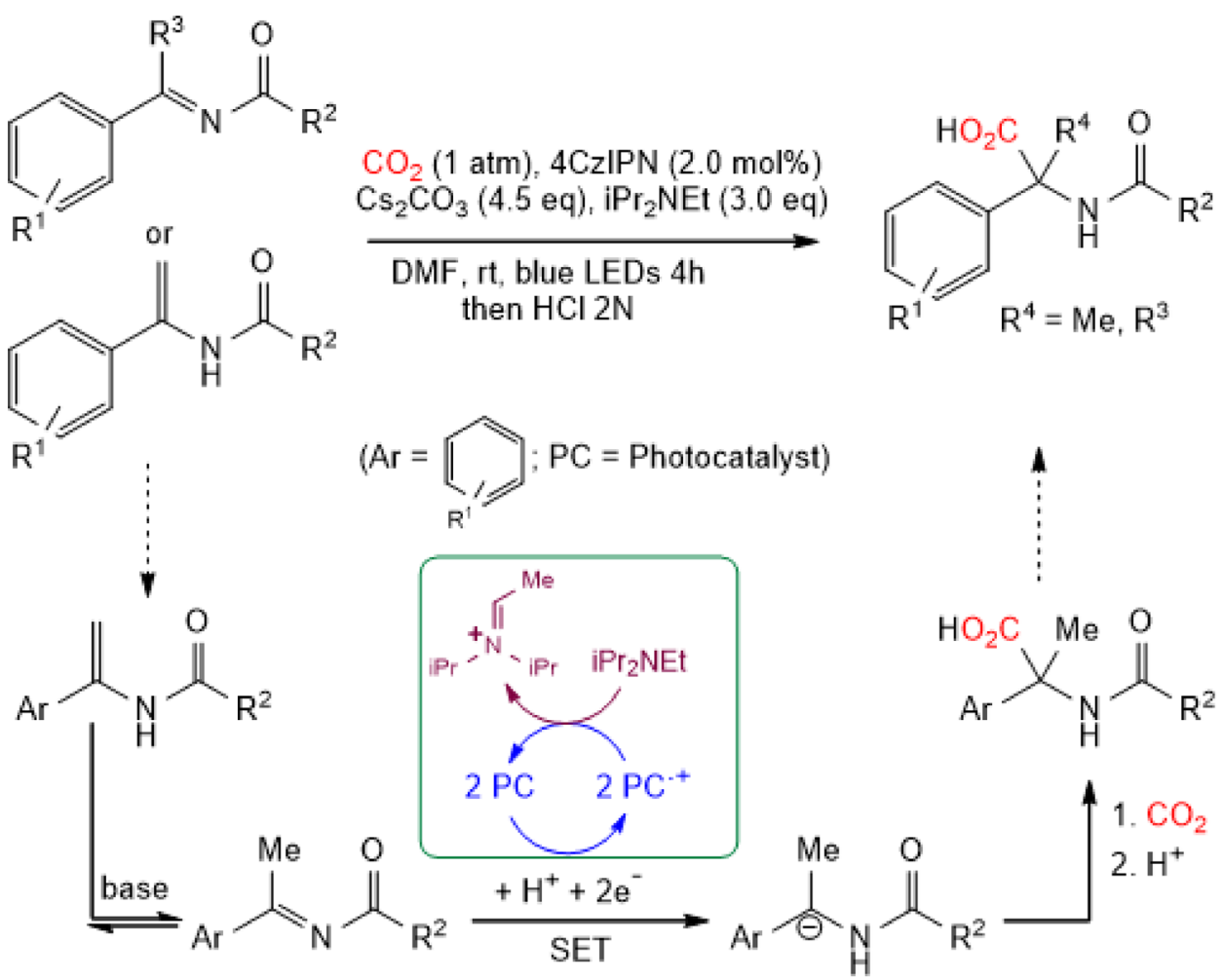<smiles>[R]C(=O)c1cc[R3](C)cc1C([R2])C</smiles><smiles>[R]C(=O)c1ccc([R])cc1C([R2])C(=O)O</smiles>

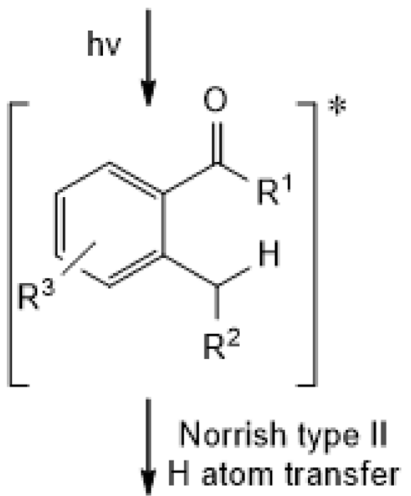<smiles>[R][R3]1ccc2c(c1)C([R2]CC)C(=O)OC2([R])O</smiles>

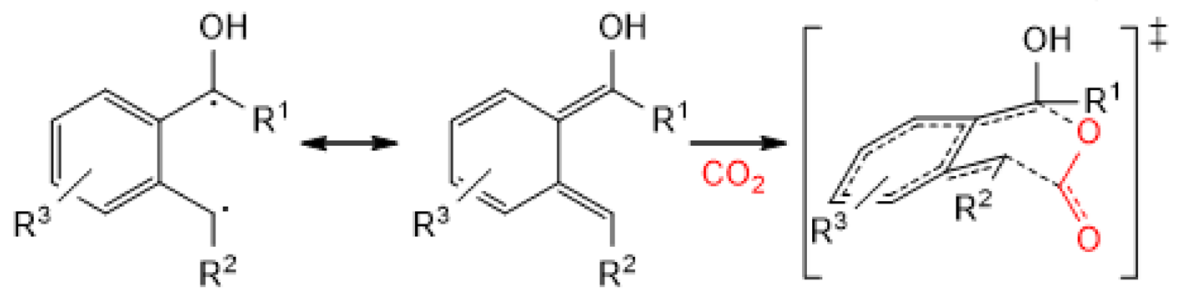


Scheme 4 Direct photoinduced electron transfer to carbon dioxide and its trapping via alpha amino radicals
Illustration 1 Mechanism of ferrocyanide photoreaction in the reduction of $\mathrm{CO}_{2}$ into useful products for evolution of life
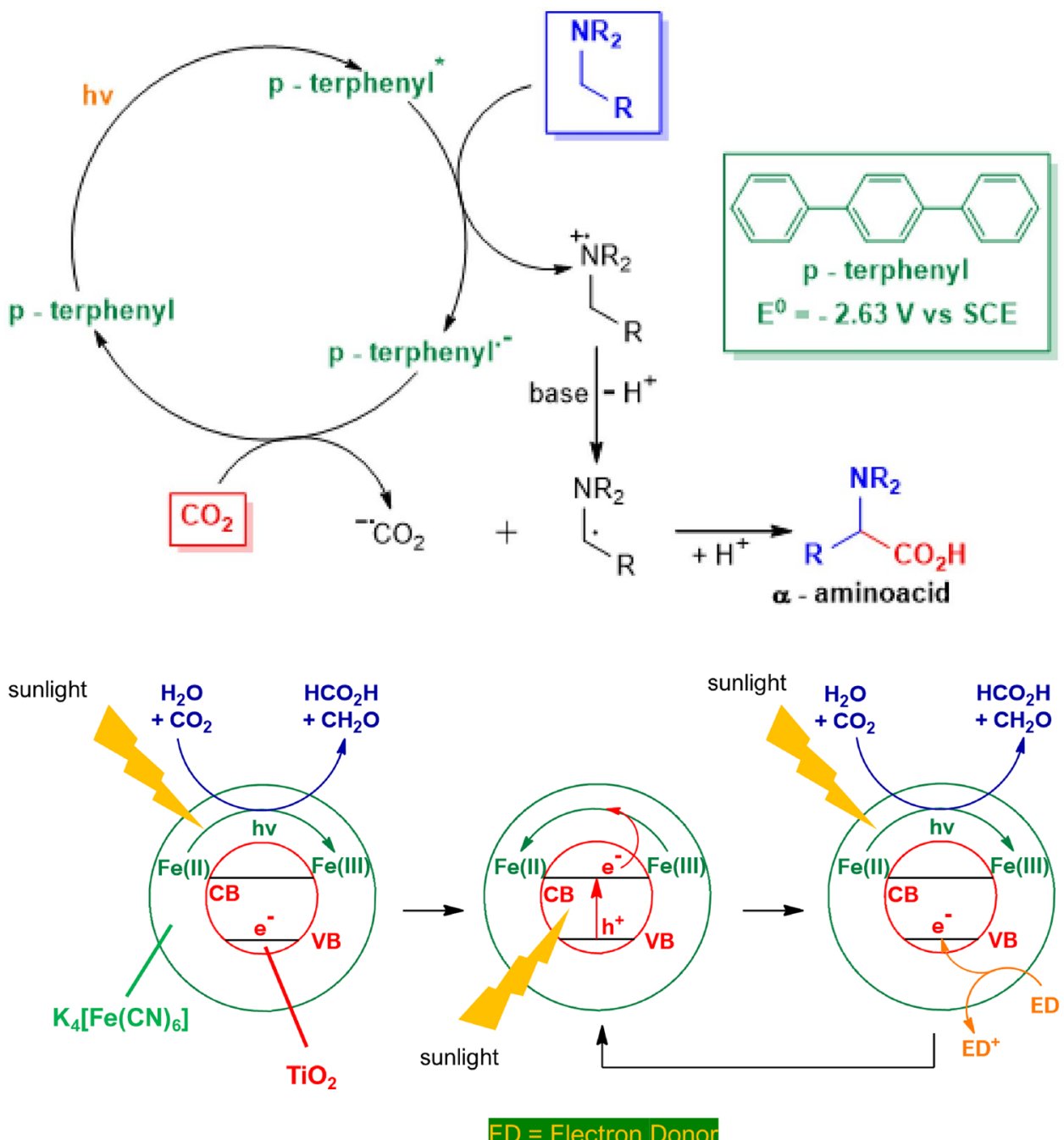

\section{Porphyrins and other nitrogen containing metal complexes}

Porphyrins are widely represented in actual organisms and are considered prebiotically plausible photosensitizers [34-38].

Their synthesis is straightforward, and it is compatible with prebiotic environments [39]. Vesicles could be used as microreactors to drive a chemical evolution. Moreover, their synthesis could require formaldehyde [40], that is achievable through the reduction of carbon dioxide.

In this aspect, $\mathrm{Fe}$ is the metal center compared to the other elements in his family group elements also for its availability on the planet.

Photogenerated iron(0) tetraaryl porphyrin [41] can perform the photocatalytic reduction reaction under irradiation at $\lambda>280 \mathrm{~nm}$.
The photoreduction of $\mathrm{CO}_{2}$ is enhanced by the addition of a sacrificial electron donor $\left(\mathrm{Et}_{3} \mathrm{~N}\right)$. The electron donor is also useful for the reduction of iron (III) to iron( 0$)$, that is the active species. The reaction has a good catalytic activity and selectivity toward the formation of $\mathrm{CO}$. Hydrogen is also observed as a subproduct due to the interaction of $\mathrm{Et}_{3} \mathrm{NH}^{+}$ with iron (II) porphyrin [42]. At longer irradiation time, the porphyrin ring could undergo inactivation due to hydrogenation. Porphyrins are well studied and their modifications to improve the efficiency is a hot topic [43].

An interesting modification is the addition of a molecular "arm" lying over the metal center, giving the so-called hangman porphyrins. These classes of porphyrins possess an enhanced electrocatalytic conversion of $\mathrm{CO}_{2}$ [44].

Copper(II) imidazolate frameworks are interesting photocatalysts prepared easily by reaction of imidazole with a copper (II) salt in the presence of a base and subsequently submitted to a mild heating. Different treatments give rise to 
frameworks having different band gaps. [45]. These photocatalysts can reduce carbon dioxide to methanol by irradiation with visible light [46]. The highest yield of methanol formation was $1712.7 \mu \mathrm{mol} / \mathrm{g}$ obtained by irradiating the solution with a filtered (>400 nm) $500 \mathrm{~W}$ Xe lamp. Authors discuss this result comparing the structure of the catalyst with the boron carbide $\left(\mathrm{C}_{3} \mathrm{~N}_{4}\right)$ polymer (Illustration 2).

\section{Oxide semiconductors}

A diversity of semiconductors such as $\mathrm{TiO}_{2}, \mathrm{ZnO}, \mathrm{CdS}$ and $\mathrm{In}_{2} \mathrm{O}_{3}$, have been widely used as photocatalysts for the conversion of $\mathrm{CO}_{2}$ in past decades [47].

The redox reaction mechanism looks straightforward at a first glance:

$$
\mathrm{CO}_{2} \underset{+2 \mathrm{H}^{+}}{\stackrel{+2 \mathrm{e}^{-}}{\longrightarrow}} \mathrm{HCOOH} \underset{\substack{+2 \mathrm{H}^{+} \\-\mathrm{H}_{2} \mathrm{O}}}{\stackrel{+2 \mathrm{e}^{-}}{\longrightarrow}} \mathrm{CH}_{2} \mathrm{O} \stackrel{+2 \mathrm{e}^{-}}{\stackrel{+2 \mathrm{H}^{+}}{\longrightarrow}} \mathrm{CH}_{3} \mathrm{OH} \stackrel{+2 \mathrm{e}^{-}}{\stackrel{+2 \mathrm{H}^{+}}{\longrightarrow}} \mathrm{CH}_{4}
$$

However, since a semiconductor can give only one electron for each photon absorbed, we must consider the formation of unstable intermediates having an odd number of electrons.

Shkrob [12] suggested the formation of two carbon intermediates like glyoxal and glycolaldehyde, which could be detected as byproducts. Surprisingly or not, these two compounds are of prebiotic interest (and biological interest).

Among all the semiconductors, $\mathrm{TiO}_{2}$ has been extensively used widely due to its higher stability, reduced toxicity, and low costs [48-50]. When compared to pristine $\mathrm{TiO}_{2}$, functionalized $\mathrm{TiO}_{2}$ with ethanolamine groups is more effective in the chemisorption of $\mathrm{CO}_{2}$ molecules. Ethanolamine moieties on the $\mathrm{TiO}_{2}$ surface have the double role of increasing the local concentration of carbon dioxide molecules chemisorbed as carbamate and lowering the reduction potential [24]. With this catalyst, carbon dioxide is converted into methane and carbon monoxide.

Other than $\mathrm{TiO}_{2}$, some more photocatalysts play a walkon part in the reduction of $\mathrm{CO}_{2}$.

As an example, $\mathrm{CeO}_{2}$, an n-type semiconductor having a wide band gap, could be useful to fabricate heterojunction semiconducting materials. A heterojunction with $\mathrm{Co}_{3} \mathrm{O}_{4}$ enhances the efficacy of visible-light absorption by shrinking the band gap in which that $\mathrm{p}-\mathrm{n}$ junction can smartly work in the reduction of $\mathrm{CO}_{2}$ in a nicer way because of the conduction band potential is more positive. The combined photocatalyst possesses a reduced band-gap value of $2.07 \mathrm{eV} . \mathrm{Co}_{3} \mathrm{O}_{4} / \mathrm{CeO}_{2}$ acts as a photoreducing catalyst in the reduction of $\mathrm{CO}_{2}$ to methanol and ethanol with improved photocatalytic activity [51].

Also, $\mathrm{Cu}_{2} \mathrm{O}$ can create a heterojunction with $\mathrm{CeO}_{2}$ giving higher stability, non-toxicity, and wide band gap [52].
$\mathrm{Cu}_{2} \mathrm{O}$ could be efficiently coupled also with hematite producing a photocatalyst active in the visible-light spectrum for the reduction of $\mathrm{CO}_{2}$ to $\mathrm{CO}$ in the gas phase [53].

\section{Sulfides}

Elemental sulfur and metal sulfides are of great interest as potential prebiotic photocatalysts for the reductive conversion of $\mathrm{CO}_{2}$ to potentially prebiotic important intermediate, such as formate and formaldehyde, due to their abundance in the Primordial Earth and their photocatalytic activities (Illustration 3).

The metal linked to the sulfide — usually a heavy metalcan coordinate carbonate or bicarbonate, but usually not free $\mathrm{CO}_{2}$, driving its reduction, so that the reaction takes part better in a neutral or only weakly acidic environment [54].

Carbonates and bicarbonates interact specifically with some crystallographic structures of the particles of the catalyst, so that the physical form of the catalyst itself has a great influence on the reduction efficiency. Bulk materials are in most cases inactive for photocatalytic conversions, but nanostructured material may lead to significant improvement of photocatalytic performance, due to the fine tuning of the band gap and to kinetic factors such as suppression of electron/hole pair recombination and a larger catalytically active surface area [55]. Colloidal materials, that are nanostructures and could be found in primordial waters [56], are particularly efficient at this regard [57].

Semiconductor minerals such as heavy metal sulfides may be exceptionally active $\mathrm{C}(+\mathrm{IV})$ to $\mathrm{C}(+\mathrm{II})$ photocatalysts, even at reduced temperatures. Their photoreducing ability is due to the conduction band electrons formed during 
Illustration 2 Mechanism of metal complexes having nitrogen containing ligands with porphyrin photoreaction in the reduction of $\mathrm{CO}_{2}$ into useful products for evolution of life

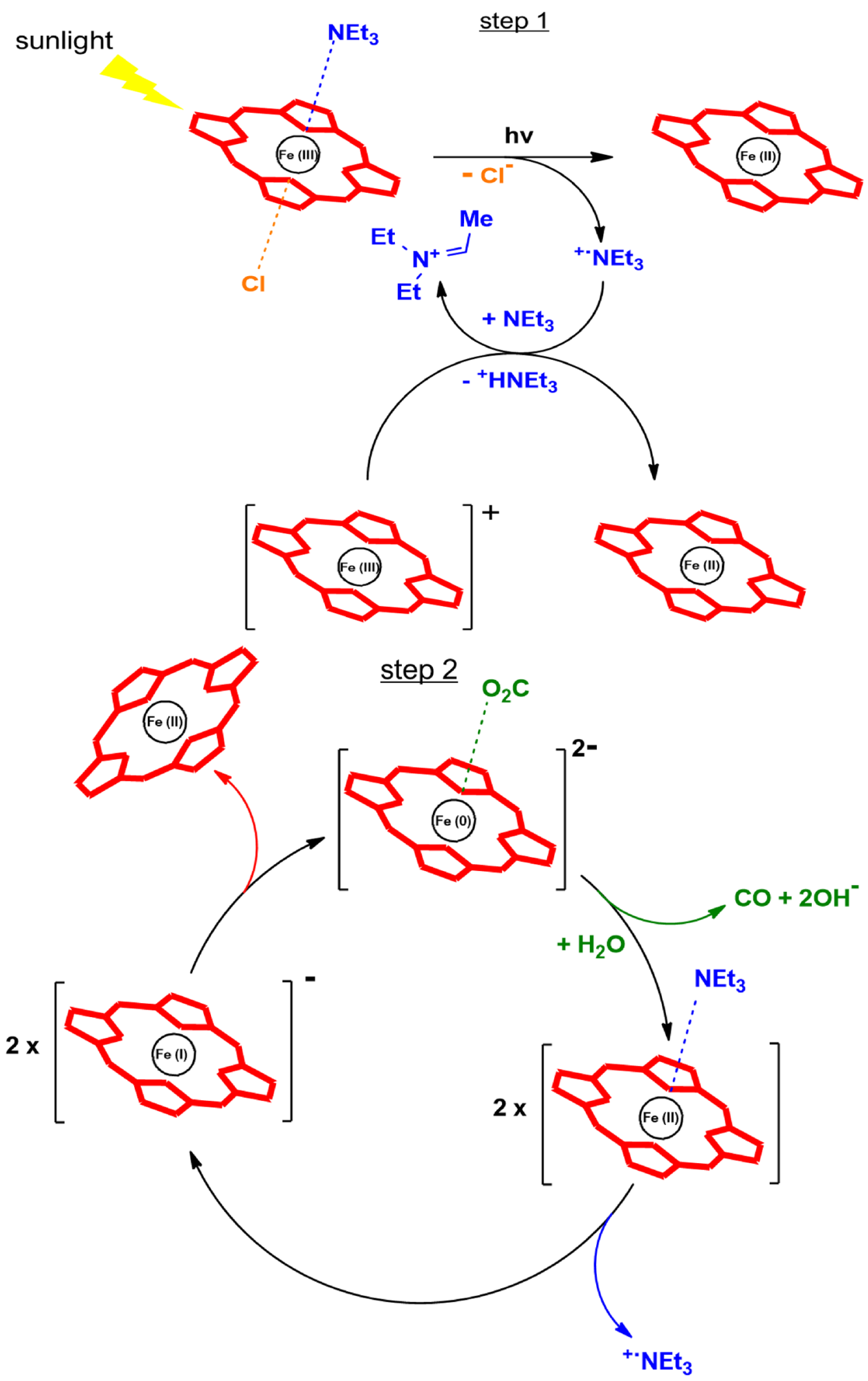

ultraviolet (UV) irradiation. When a photon with an energy exceeding the band gap is absorbed, an electron from the valence band is excited into the conduction band, while a hole remains in the valence band. Semiconductors having a conduction band that is poised at a sufficiently negative voltage are thermodynamically capable of reducing carbon dioxide [58].

Different metal catalysts result in differences in the activity and selectivity of the $\mathrm{CO}_{2}$ because of the differences in the adsorption strength of the intermediates. 


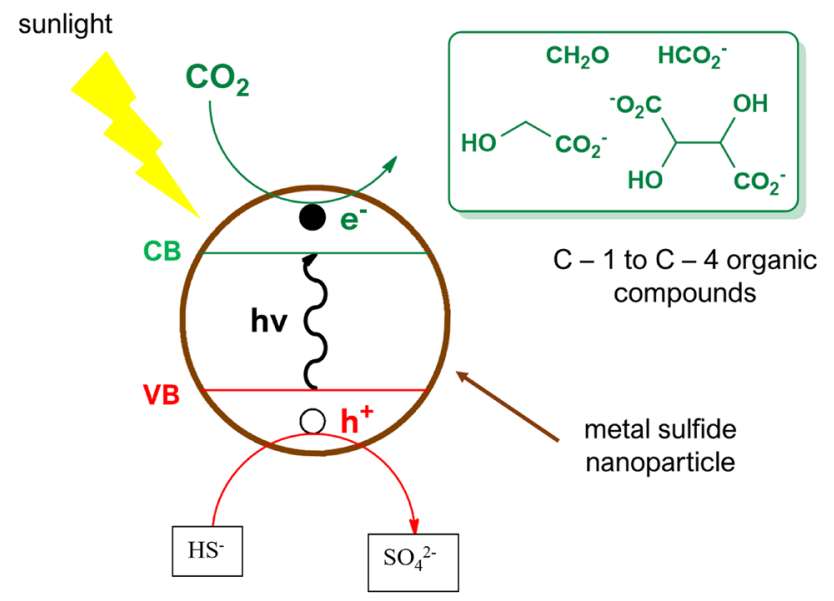

Illustration 3 Mechanism of sulfides' photoreaction in the reduction of $\mathrm{CO}_{2}$ into useful products for evolution of life

Basing to the selectivity for final products, according to literature [59], the metal catalysts can be classified into four categories:

(1) $\mathrm{Cd}, \mathrm{Hg}, \mathrm{Sn}, \mathrm{In}, \mathrm{Bi}, \mathrm{Pb}, \mathrm{Pd}$, etc., which easily produce $\mathrm{HCOO}$ intermediate, and lead to formate as the main product.

(2) $\mathrm{Au}, \mathrm{Ag}, \mathrm{Zn}$, etc., that due to the weak $\mathrm{CO}$ adsorption capacity, produce $\mathrm{CO}$ as main product.

(3) $\mathrm{Ni}, \mathrm{Fe}, \mathrm{Si}, \mathrm{V}, \mathrm{Pt}$, etc., mainly able to produce $\mathrm{H}_{2}$ due to the low hydrogen evolution potential.

(4) $\mathrm{Cu}$ that, under different conditions, can produce up to 16 different carbon-containing compounds.

Moreover, mixed metal catalysts having multiple binding sites for intermediate species will have a great influence on the performance of the catalyst.

Sulfur atoms greatly contribute to the reduction reaction, due to the intrinsic characteristic of this element. For example, $\mathrm{S}$ has small electronegativity, strongly coordinates with the metal elements, and has the capacity to bond with itself to form a chain-shaped polysulfide ion, namely $\mathrm{S}_{\mathrm{n}}{ }^{2-}$. Due to the various bonding modes of $\mathrm{S}$ atoms, the structure of sulfides tends to be diversified and complicated, which means that $\mathrm{S}$ is a versatile candidate as a modifier for electrocatalyst fields. The $\mathrm{S}$ atom can effectively suppress the hydrogen evolution reaction (HER), which occurs as a competitive reaction and significantly influences the absorption and desorption strength of $\mathrm{CO}_{2}$ reduction intermediates [59]. Moreover, sulfur accelerates $\mathrm{CO}_{2}$ reduction by a unique mechanism, as it can also enhance the activation of water, forming hydrogen species that can readily react with $\mathrm{CO}_{2}$ to produce formate [60].

Elemental sulfur $\left(\mathrm{S}^{0}\right)$ has been investigated as a potential photocatalyst for $\mathrm{CO}_{2}$ reduction, also considering that in modern and ancient volcanic hydrothermal systems on the surface of Earth, it is a quite abundant element. As a typical nonmetallic semiconducting element, $\mathrm{S}^{0}$ can photo-reduce $\mathrm{CO}_{2}$ into formic acid under ultraviolet (UV) light below $280 \mathrm{~nm}$. The semiconducting $\mathrm{S}$ is indicated to have a direct band gap of $4.4 \mathrm{eV}$. The UV-excited $\mathrm{S}^{0}$ produces photoelectrons with a highly negative potential of $-2.34 \mathrm{~V}$ (versus NHE, $\mathrm{pH} 7$ ), which could reduce $\mathrm{CO}_{2}$ after accepting electrons from electron donors such as reducing sulfur species. Simultaneously, UV light breaks sulfur bonds, allowing the adsorption of charged carbonates onto $\mathrm{S}^{0}$ and assisting their photoreduction. Assuming that terrestrial hot springs covered $1 \%$ of primitive Earth's surface, $\mathrm{S}$ could have produced up to $10^{9} \mathrm{~kg} /$ year $\mathrm{HCOOH}$ within 10 -cm-thick photic zones, underlying its remarkable contributions to the accumulation of prebiotic biomolecules [61].

Of the common sulfide-based semiconductors, $\mathrm{ZnS}$ and $\mathrm{MnS}$ have the important property that their conduction bands are placed at highly reducing positions, respectively, of -1.04 and $-1.19 \mathrm{~V}$ versus the NHE (normal hydrogen electrode).

The large overpotential for carbon fixation by $\mathrm{ZnS}$ and $\mathrm{MnS}$ leads to high photoreaction rates. The difference in band gap between $\mathrm{ZnS}(3.6 \mathrm{eV}, 344 \mathrm{~nm})$ and $\mathrm{MnS}(3.0 \mathrm{eV}$, $413 \mathrm{~nm}$ ) suggests that MnS may use the solar spectrum more efficiently.

At this regard, photoreduction of $\mathrm{C}(+\mathrm{IV})$ as bicarbonate was used as a probe to investigate the photoelectrochemical properties of alabandite (MnS) colloidal particles, that is found in epithermal sulfide vein deposits and in anoxic laminated sediments. Photoreduction occurs and formate is the initial photoproduct. A quantum efficiency of $4.2 \%$ is obtained ( $\mathrm{pH}$ 7.5). The quantum efficiency is temperatureindependent from 298 to $328 \mathrm{~K}$. In addition to formate, longer chain carbon products such as acetate and propionate are also produced, although to a lesser extent. Longer chain organic molecules that contain oxygenated functional groups were also identified, although these data can be disputed. These results suggest that some prebiotic syntheses could have occurred via photoelectrochemical reactions on semiconducting minerals [58].

Mixed molybdenum sulfides catalysts were also realized. In particular, n-type $\mathrm{Bi}_{2} \mathrm{~S}_{3}$ nanorods were wrapped with twodimensional (2D) p-type $\mathrm{MoS}_{2}$ sheets, which have good light absorption properties.

The designed $\mathrm{p}-\mathrm{n}$ junction $\mathrm{Bi}_{2} \mathrm{~S}_{3} / \mathrm{MoS}_{2}$ composite exhibited enhanced light absorption over the entire wavelength range, and higher carbon dioxide adsorption capacity and photocurrent density compared to the single catalysts. Consequently, the activity of the $1: 1 \mathrm{Bi}_{2} \mathrm{~S}_{3} / \mathrm{MoS}_{2}$ composite catalyst for the photocatalytic reduction of carbon dioxide was more than 20 times higher than that of the single catalysts under visible-light irradiation at $\leq 400 \mathrm{~nm}$, with partial selectivity for $\mathrm{CO}$ conversion. This is attributed to 
the $\mathrm{p}-\mathrm{n}$ heterojunction: the high light absorption of $\mathrm{n}-\mathrm{Bi}_{2} \mathrm{~S}_{3}$ accelerated electron excitation, and the electron affinity of the $2 \mathrm{D}$ sheet $\mathrm{p}-\mathrm{MoS}_{2}$, which quickly absorbed excited electrons, resulted in effective charge separation. This ultimately improved the catalytic performance by continuously supplying catalytically active sites to the heterojunction interfaces [62].

Regarding $\mathrm{ZnS}$, freshly prepared colloidal suspensions effectively catalyze the photoreduction of $\mathrm{CO}_{2}$ in water at pH 7 with $\mathrm{NaH}_{2} \mathrm{PO}_{2}$ in the coexistence of $\mathrm{Na}_{2} \mathrm{~S}$ under UV irradiation. With competitive $\mathrm{H}_{2}$ evolution, formate and a very small quantity of $\mathrm{CO}$ were formed with the apparent quantum yield $\phi=0.24$ at $313 \mathrm{~nm}$, where $\mathrm{H}_{2} \mathrm{PO}_{2}{ }^{-}$was quantitatively photooxidized to $\mathrm{HPO}_{3}{ }^{2-}$. The efficiency strongly depends on the $\mathrm{pH}$ of the system, the preparation methods of $\mathrm{ZnS}$ photocatalysts, and synergistic effects of electron donors. Quantized $\mathrm{ZnS}$ crystallites with low density of surface defects are indispensable for the effective $\mathrm{CO}_{2}$ reduction. The synergistic effect in the use of both $\mathrm{SH}^{-}$and $\mathrm{H}_{2} \mathrm{PO}_{2}{ }^{-}$ions is essential for the reaction to take place [57, 63].

Aqueous solutions of $\mathrm{CO}_{2}$ containing tetramethylammonium chloride photolysed with visible light in the presence of colloidal $\mathrm{ZnS}$ yielded tartaric acid, glyoxylic acid, oxalic acid, formic acid, and formaldehyde [64], showing that the presence of an amine-modified catalyst can lead to a wide range of different prebiotically interesting compounds.

Zinc sulfide was also modified by $\mathrm{Ru}, \mathrm{Cd}$, or as a microcrystallite, or supported on $\mathrm{SiO}_{2}$, always observing formate formation [65]. The use of the modifier stabilizes the catalyst, improves its light absorption efficiency, and modulates the band gap.

Highly selective photoelectrochemical $\mathrm{CO}_{2}$ reduction to formate ( $>80 \%$ selectivity) in water was successfully achieved by combining $\mathrm{Cu}_{2} \mathrm{ZnSnS}_{4}$ (CZTS) with a metalcomplex electrocatalyst. CZTS, a sulfide semiconductor that possesses a narrow band gap and consists of earth-abundant elements, is demonstrated to be a candidate photoabsorber for a $\mathrm{CO}_{2}$ reduction hybrid photocatalyst [66]. This shows that the electron donor can be either a compound present in solution, or an electrode surface, showing that the most critical element is not the oxidizable substrate but more commonly the catalyst itself, as different oxidizable substrates can be used without loss of efficiency.

Speaking of sulfides different from that $\mathrm{Mn}$ or $\mathrm{Zn}$ based, the photocatalytic reduction of carbon dioxide on CdS particles with and without surface modification by several kinds of thiol compounds was investigated in various solvents. Formate and carbon monoxide were obtained as the major reduction products, and the ratio of the former to the latter was largely influenced by the solvents when naked cadmium sulfide was used as the photocatalyst, and by increasing the dielectric constant of the solvent, the ratio increased. Even if CdS particles were modified by thiol compounds, the effect of the solvent was not eventually altered, but the ratio of formate to carbon monoxide became greater by increasing the surface modification of CdS. The observed effect of the surface modification of CdS is interpreted in terms of involvement of $\mathrm{Cd}$ sites adjacent to surface vacancies of $\mathrm{CdS}$ photocatalysts in adsorption of anion radicals of $\mathrm{CO}_{2}$ [67].

As a photocatalyst active for the $\mathrm{CO}_{2}$ conversion, $\mathrm{CdS}$ can also do its work when used as an electrocatalyst [57, 63, 68]. We report therein the literature's results obtained by the use of some potentially prebiotic metal sulfides as electrocatalyst for the $\mathrm{CO}_{2}$ reduction, as they can be potentially active as photocatalysts [69, 70], although careful experimental conditions tuning must be performed and discordant results can be obtained when shifting from electrocatalysis to photocatalysis and vice versa [71]. A study by Kitadai et al. using various single-metal sulfides $\left(\mathrm{Ag}_{2} \mathrm{~S}, \mathrm{CdS}, \mathrm{CoS}, \mathrm{CuS}, \mathrm{FeS}\right.$, $\mathrm{MnS}, \mathrm{MoS}_{2}, \mathrm{NiS}, \mathrm{PbS}, \mathrm{WS}_{2}$, and $\mathrm{ZnS}$ ) demonstrated that $\mathrm{CdS}$ and $\mathrm{Ag}_{2} \mathrm{~S}$ function as excellent $\mathrm{CO}$ production catalysts [72]. Among the results reported in the literature, these concerning iron sulfides, however, are of particular interest due to their abundance in the primordial environment.

The mineral greigite, found in the chimney cavities of hydrothermal vent, presents similar surface structures to the active sites found in many modern-day enzymes. Electrocatalytic reduction of $\mathrm{CO}_{2}$ to $\mathrm{CO}$ and $\mathrm{CH}_{4}$ on greigite $\left(\mathrm{Fe}_{3} \mathrm{~S}_{4}\right)$ under simulated alkaline hydrothermal vent conditions was described. As $\mathrm{CO}_{2}$ reduction will not proceed without overcoming the high energetic barrier associated with the first electron uptake step $(-1.9 \mathrm{~V}$ vs. the standard hydrogen electrode, SHE at $\mathrm{pH} 7$ ) and also competes with the thermodynamically and kinetically more favorable reduction of protons to $\mathrm{H}_{2}$, the Faraday efficiency for $\mathrm{CO}$ production is low $(<0.02 \%$ in total at $-1.3 \mathrm{~V}$ vs. SHE) at $\mathrm{pH} 5.5$. However, by doping $\mathrm{FeS}$ with $\mathrm{Ni}$ to form $\mathrm{FeNi}_{2} \mathrm{~S}_{4}$ (violarite), the $\mathrm{CO}_{2}$ electroreduction selectivity is enhanced by $\sim 85$-fold concurrently with a lowered onset potential $(-0.5 \mathrm{~V}$ vs. SHE, $\mathrm{pH}$ 5.5) into a series of $\mathrm{C} 1-\mathrm{C} 3$ compounds, including formic acid, acetic acid, methanol, and pyruvic acid. [72]

Another study showed that particles of greigite can reduce $\mathrm{CO}_{2}$ under ambient conditions into chemicals such as methanol, formic, acetic, and pyruvic acid, supporting the Origin of Life theory on alkaline hydrothermal vents [54].

By careful adjustment of the process conditions, another mixed $\mathrm{Fe} / \mathrm{Ni}$ sulfide, pentlandite $\left(\mathrm{Fe}_{4.5} \mathrm{Ni}_{4.5} \mathrm{~S}_{8}\right)$, in addition to HER, also support the $\mathrm{CO}_{2}$ electroreduction, reaching a peak faradaic efficiency of $87 \%$ and $13 \%$ for the formation of $\mathrm{CO}$ and methane. The choice of solvent, the presence of water/ protons, and $\mathrm{CO}_{2}$ solubility are identified as key properties to adjust the balance between $\mathrm{HER}$ and $\mathrm{CO}_{2}$ reduction in favor of the latter. [54]

Also, copper sulfide, as a low-toxicity and emerging material, has broad prospects in the field of $\mathrm{CO}_{2}$ reduction 


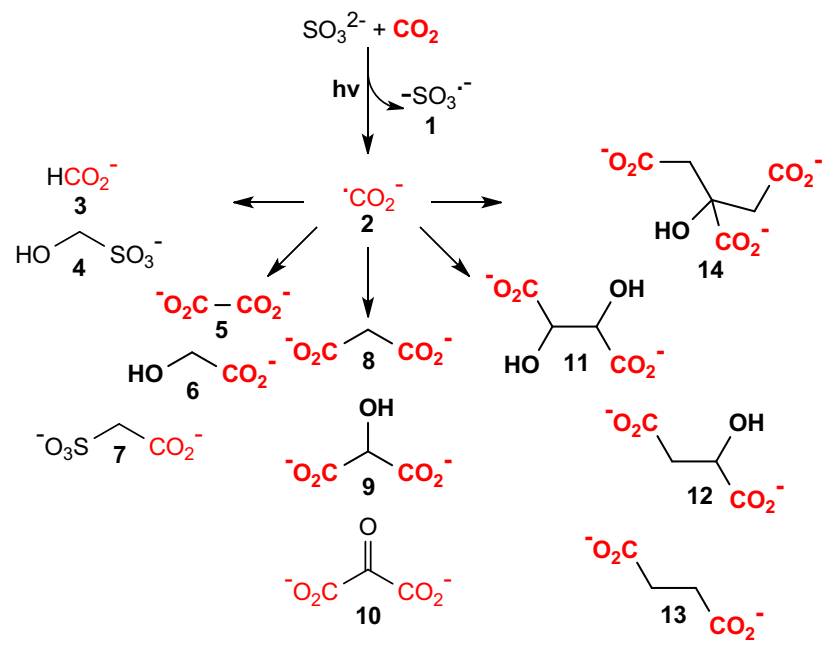

Scheme 5 Carbonaceous molecules formed through the photochemical interaction between sulfite and $\mathrm{CO}_{2}$ under $\mathrm{UV}$ irradiation

due to its unique structural and electrochemical properties. Depending on the catalyst stoichiometric composition, its shape and morphology, and the experimental conditions, different products can be obtained, such as methane, formate, or CO. Concurrent hydrogen evolution can be partially suppressed by choosing the working conditions, thus maximizing $\mathrm{CO}_{2}$ reduction [59].

More exotic devices, such as sulfur-doped indium surfaces are able to convert $\mathrm{CO}_{2}$ in formate [60] and a new class of material, that of $\mathrm{Ge}-\mathrm{S}$-In chalcogenide glass, can produce formate starting from $\mathrm{CO}_{2}$ [73].

All these results showed that the photoreduction of $\mathrm{CO}_{2}$ in a primordial environment rich of colloidal sulfur and metal sulfides is far from being a remote hypothesis, although its real contribution to the formation of prebiotic molecules is a matter of debate [74].

\section{Sulfites}

Carbon dioxide can be reduced through sulfite photochemistry. Investigations of Hadean ( $\approx 4600-4000 \mathrm{Ma})$ zircons [75] revealed that Earth at that time had an oxidizing mantle, with an important release of sulfur dioxide in the atmosphere. This resulted in the production of sulfite and bisulfite upon contact with fluvial or oceanic water bodies. In an oxygen lacking atmosphere, compatible with the prebiotic Hadean one, sulfite could be stored through precipitation and formation of minerals such as hannebachite, $\left(\mathrm{CaSO}_{3}\right) 0.1 / 2 \mathrm{H}_{2} \mathrm{O}$ [76]. These data suggest therefore a prebiotic geochemical and atmospheric scenario that in the pre-biological era supplied the environment with sulfite and bisulfite based chemical species. Sulfite ion $\mathrm{SO}_{3}{ }^{2-}$ can undergo photo-detachment of an electron [77], which is released in the solution in the solvated form (Scheme 5) [78]. The oxidation of sulfite involves the formation of $\mathrm{SO}_{3}{ }^{-} \mathrm{I}$ (Scheme 5), according to the UV light-driven reaction $\mathrm{SO}_{3}{ }^{2-} \rightarrow \mathrm{SO}_{3}{ }^{2-}+\mathrm{e}_{(\mathrm{aq})}{ }^{-}$(Illustartion 4$)$. Neta and co-workers [79] demonstrated that for the redox couple $\mathrm{SO}_{3}{ }^{2-} / \mathrm{SO}_{3}{ }^{--}$, the reduction potential vs NHE are $0.73 \mathrm{~V}$ at $\mathrm{pH}>11,0.75 \mathrm{~V}$ at $\mathrm{pH} 7,0.92 \mathrm{~V}$ at $\mathrm{pH} 4$, and $1.05 \mathrm{~V}$ at $\mathrm{pH}$ 2. Sulfite ion has thus the potential to act like a reductant by exploiting its photochemical characteristics. Similarly, $\mathrm{CO}_{2}$ can also undergo reduction through the addition of a solvated electron to give $\mathrm{CO}_{2}^{-{ }^{-}} \mathbf{2}$, according to the reaction $\mathrm{CO}_{2}+\mathrm{e}_{(\mathrm{aq})}{ }^{-} \rightarrow \mathrm{CO}_{2}{ }^{-}$. Janik and Tripathi investigated the nature of radical anion $\mathrm{CO}_{2}{ }^{--}$using pulse radiolysis
Illustration 4 Mechanism of sulfite photoreaction in the reduction of $\mathrm{CO}_{2}$ into useful products for evolution of life

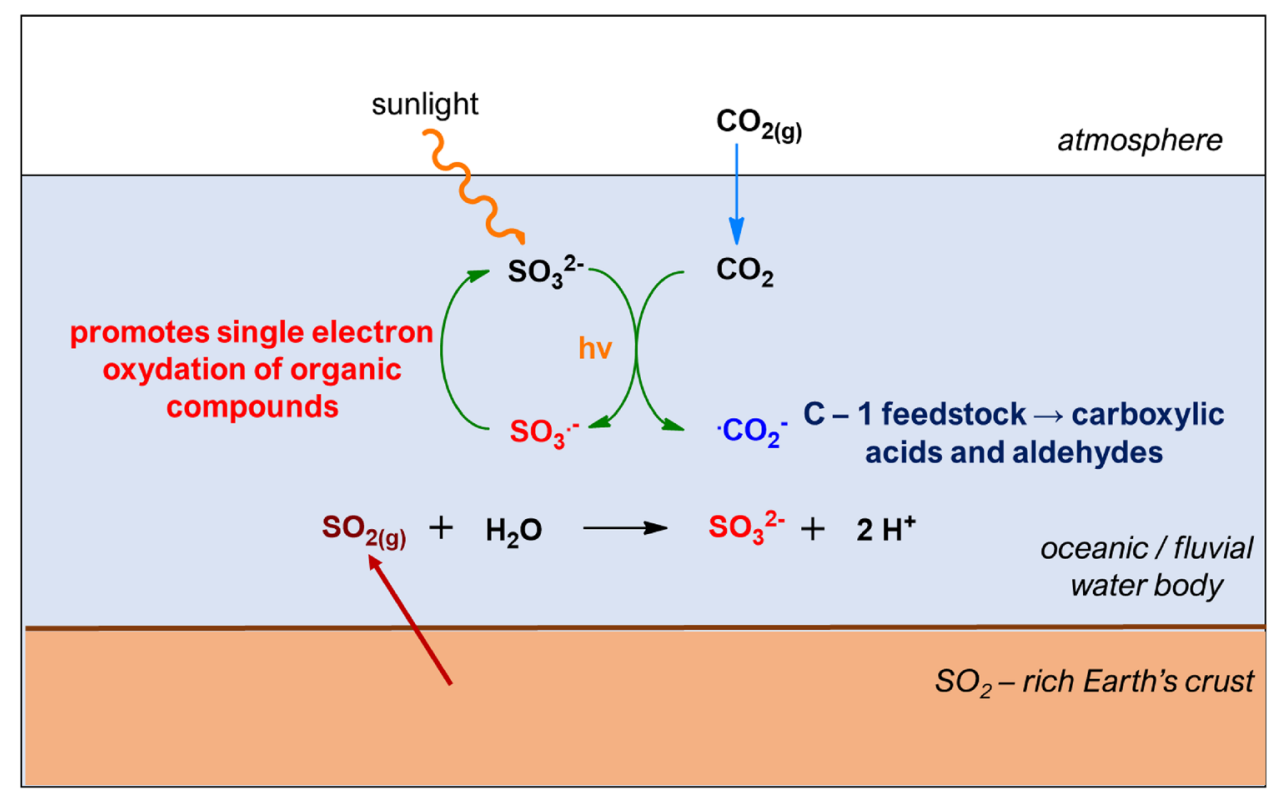


Scheme 6 Proposed mechanism for the formation of malonic acid $\mathbf{8}$ starting from carbon dioxide and sulfite in an UV irradiated environment

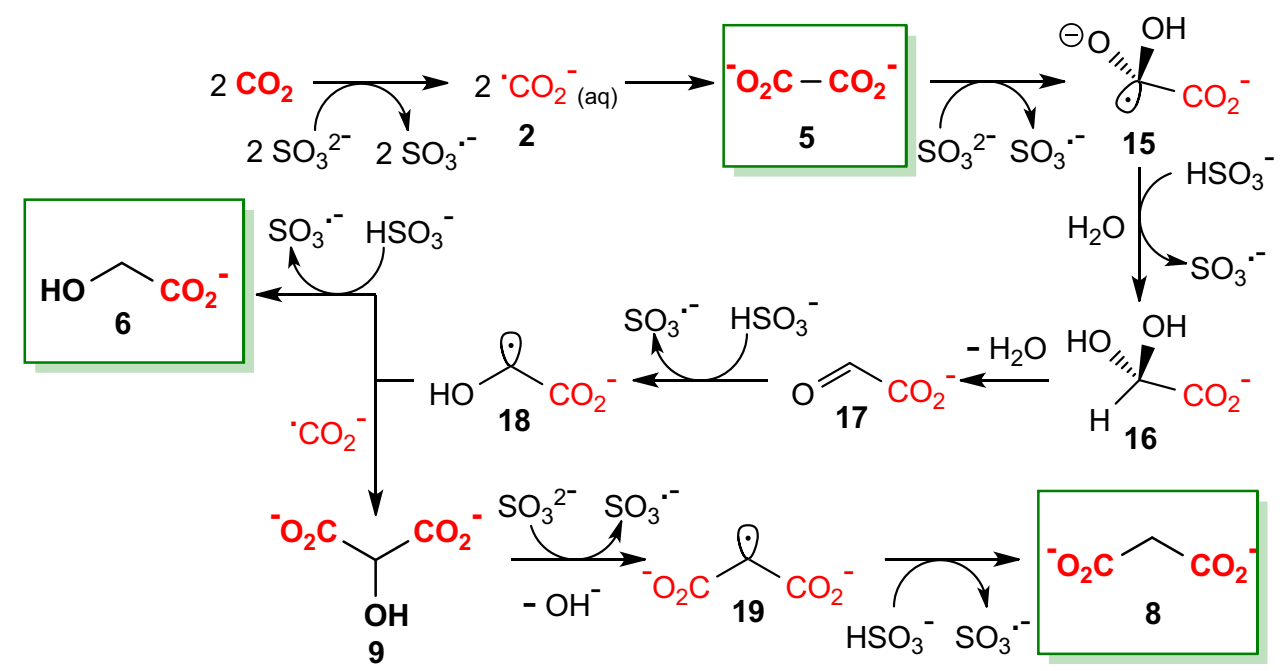

time-resolved Raman spectroscopy [80]. Starting from DFT calculation and the experimentally obtained data, it was found that 2 belongs to the $\mathrm{C}_{2 \mathrm{v}}$ point group, with a $\mathrm{OCO}$ bond angle of about $130^{\circ}$ and the unpaired electron located on the central carbon atom. This radical anion exists as the $\left[\left({ }^{\circ} \mathrm{CO}_{2}\right) \cdot\left(\mathrm{H}_{2} \mathrm{O}\right)_{4}\right]^{-}$hydrated cluster, with a calculated hydration energy of about $1.5 \mathrm{eV}$. Moreover, Roughton and Booth [81] demonstrated that oxyanions such as sulfite can catalyze the dissociation process $\mathrm{H}_{2} \mathrm{CO}_{3} \rightarrow \mathrm{CO}_{2}+\mathrm{H}_{2} \mathrm{O}$, increasing the $\mathrm{CO}_{2}$ abundance in water. These theoretical and experimental data demonstrate that sulfite has the potential to reduce carbon dioxide in aqueous solution [82].

Recently, Sutherland, Sasselov, and co-workers [83] have investigated this approach to the carbon dioxide photochemical reduction. Starting from a solution of $\mathrm{NaHSO}_{3}$ and $\mathrm{NaHCO}_{3}$, they were able to produce a complex mixture of organic chemical compounds. Most of them corresponded or were similar to the carboxylic acids observed in extant metabolic cycles found in nature (Scheme 5).

These products can be formed through a complex network of reactions. In the simplest possible step, carbon dioxide is converted into $\mathrm{CO}_{2}{ }^{-}$, which then undergoes a hydrogen atom transfer (HAT) in the presence of $\mathrm{SO}_{3}{ }^{2-}$, UV photons, and water to give formate 3 . However, further reduction of formate is slow and reversible, so that radical anions $\mathbf{2}$ can combine to give oxalate $\mathbf{5}$. Oxalate $\mathbf{5}$ is reduced much faster than formate [83], and this process promotes the formation of products containing up to six carbon atoms. The proposed pathway by which complex carboxylic acids can be produced involves solvated aqueous electrons, sulfite anion radical, and other species derived from $\mathrm{CO}_{2}{ }^{-} \mathbf{2}$ (Scheme 6).

The key steps are the reduction of oxalate $\mathbf{5}$ and the formation of glyoxylate $\mathbf{1 7}$, from which tartronate $\mathbf{9}$ is derived, providing eventually malonate $\mathbf{8}$. Carbon dioxide sulfitemediated reduction shows a characteristic product distribution time lapse: reduction of $\mathrm{CO}_{2}$ furnishes an initial high concentration of formate, but when the formation and subsequent reduction of oxalate takes over, glycolate $\mathbf{6}$ and tartronate $\mathbf{9}$ are the major products. Further UV irradiation provides for the build-up of malonate $\mathbf{8}$ which is eventually the most abundant product: this carboxysulfitic chemistry yields thus malonate $\mathbf{8}$ in a converging manner, although in the reaction network, several equilibria are still present. This carbon dioxide fixation pathway leads to the formation of $\mathrm{C}_{2}-\mathrm{C}_{4}$ products even if the sulfite supply in the reaction mixture is reduced, thus supporting a realistic geochemical prebiotic environment in which eventual deposits of sulfite salts would not have been uniformly distributed on the soil and both fluvial and oceanic water bodies.

Furthermore, carbon dioxide reduction products were obtained using an UV light source similar to the wavelengths solar spectrum present on Hadean Earth [84], making again the sulfite a plausible prebiotic reducing agent toward $\mathrm{CO}_{2}$. Apart from this, sulfite does not act as a mere stoichiometric reductant, because it leads to the formation of molecules such as oxalate $\mathbf{5}$, mesoxalate $\mathbf{1 0}$, and glyoxylate $\mathbf{1 7}$ that undergo Norrish type-I reactions providing the system of radical anions 2 . In this way, further molecules can be produced starting from the first ones.

Particularly interesting is the photochemistry elucidated from Sutherland and co-workers that is based on the glycolate previously obtained from $\mathrm{CO}_{2}$ through sulfite oxidation [83]. Irradiation of glycolate with both $254 \mathrm{~nm}$ UV light and Hadean Sun-like UV source resulted in the formation of malate 12, succinate 13, and citrate $\mathbf{1 4}$ (Scheme 7).

In these chemical steps, glycolate acts as a $\mathrm{C}_{2}$ unit through the key tartrate intermediate 11, which upon reduction and combination with radical 21, provides citrate $\mathbf{1 4}$ after two sulfite-mediated reductions. Reductive loss of hydroxide ion through SET-mediated oxidation of sulfite yields carboxymethyl radical 20 by which both malate $\mathbf{1 2}$ and succinate $\mathbf{1 3}$ are obtained. 
Scheme 7 Glycolate photochemistry mediated by sulfite ions

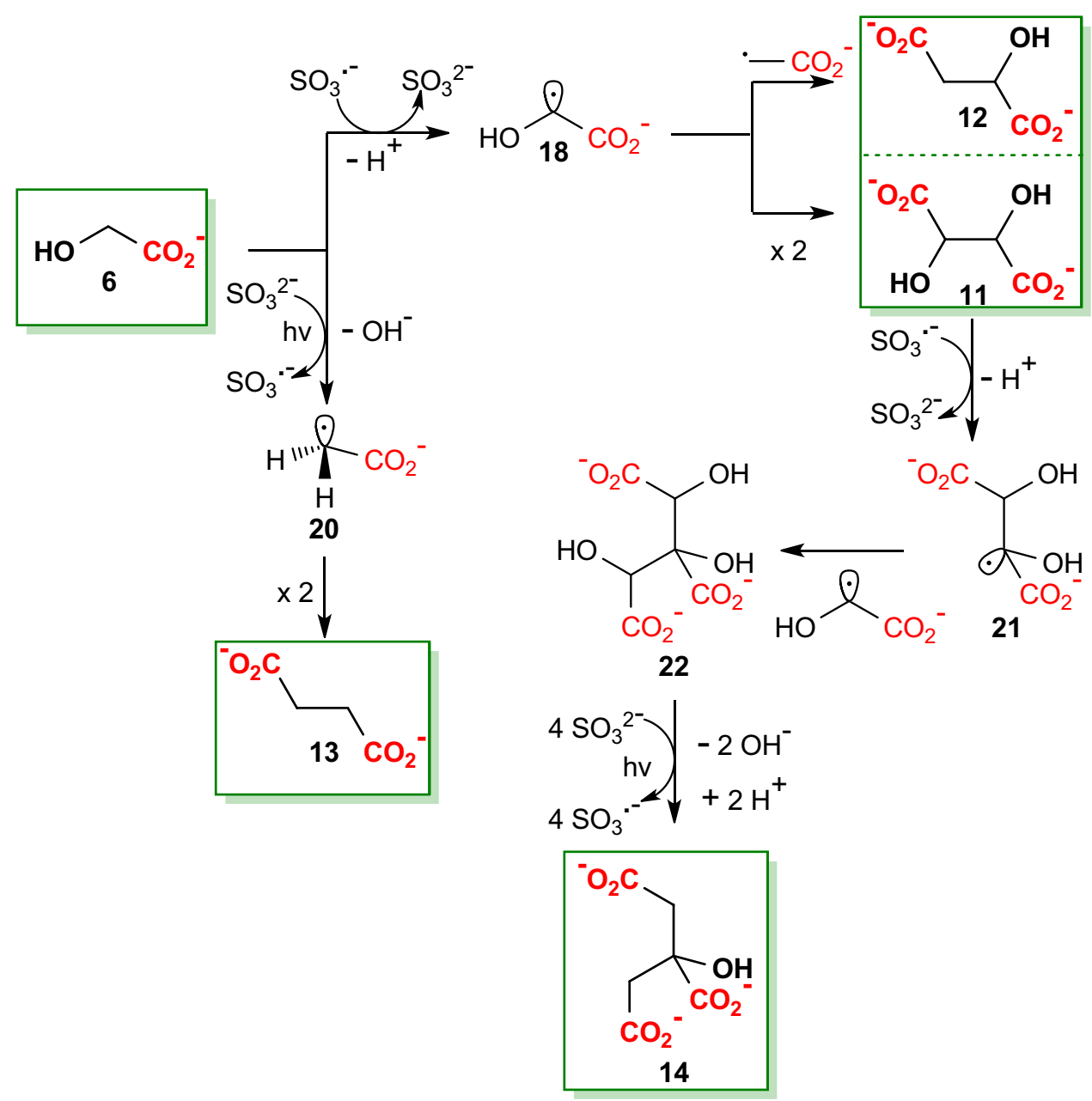

Further investigations conducted on this chemistry by Sutherland and co-workers have shown that the glycolatebased aforementioned pathway is not affected by the presence of nitrogen compounds [83]: this expands the set of prebiotic compounds chemically compatible and noninterfering with these transformations. Since succinate, malate, and citrate together with oxalate are key intermediates in the Krebs cycle, sulfite-mediated photochemical $\mathrm{CO}_{2}$ reduction could have provided primordial synthetic mechanisms starting from which extant metabolic cycles developed. Tartrate $\mathbf{1 1}$ eventually may also be a source of glycolaldehyde. Its possible dehydration to give oxaloacetate and oxidation to dihydroxy fumarate, that spontaneously loses two molecules of carbon dioxide, could provide glycolaldehyde [83, 85]. The possible conversion of tartrate to formaldehyde could represent an interesting connection between carboxylic acids and carbohydrates prebiotic chemistry. Furthermore, bisulfite, which is present (despite in little amounts) in aqueous solutions of sulfite, reacts with formaldehyde to give hydroxymethanesulfonate (HMS), which precipitates and forms crystals when is concentrated in aqueous solutions [84]. This mechanism is thought to have played an important role in formaldehyde and other small carbohydrates sequestration and concentration, supporting the primordial carbohydrate chemistry [76]. Ritson et al. [84] demonstrated that aldehyde adducts of bisulfite can lead to the formation of relevant prebiotic heterocycles, and that sulfonates could have been fundamental for protection of these molecules in the Hadean eon. In summary, it becomes apparent that sulfite through the combination of carboxysulfitic and bisulfite adducts chemistry could have really been a major player in the carbon dioxide reductive fixation and subsequent synthesis of carboxylic acid and carbohydrates from a prebiotic point of view.

\section{Conclusions and outlook}

Carbon dioxide is the endpoint of combustion of carboncontaining compounds and an unwanted product causing the greenhouse effect. However, carbon dioxide is also a big deal for photoautotrophs to kick off and maintain life on the Earth. If complex life forms exist on Earth, it is due 
to the solar light harvesting of these organisms. Therefore, an important and essential step in the origins of life is the photoreduction of carbon dioxide. This coincides with the actual efforts in the carbon dioxide reduction processes. Prebiotic conditions are synonymous to simple compounds readily available on Earth. Possibly, this is equivalent to choosing the simplest methodologies found in the literature for the $\mathrm{CO}_{2}$ photoreduction. Hopefully this collection of works might be of inspiration for both areas. With a look to the future and parallelly to what happened in biology, scientists could achieve an artificial chemical evolution toward the goal to obtain clues for life's origin and/or to obtain more performant photocatalysts.

\section{Declarations}

Conflict of interest There are no conflicts to declare.

Open Access This article is licensed under a Creative Commons Attribution 4.0 International License, which permits use, sharing, adaptation, distribution and reproduction in any medium or format, as long as you give appropriate credit to the original author(s) and the source, provide a link to the Creative Commons licence, and indicate if changes were made. The images or other third party material in this article are included in the article's Creative Commons licence, unless indicated otherwise in a credit line to the material. If material is not included in the article's Creative Commons licence and your intended use is not permitted by statutory regulation or exceeds the permitted use, you will need to obtain permission directly from the copyright holder. To view a copy of this licence, visit http://creativecommons.org/licenses/by/4.0/.

\section{References}

1. Cai, T., Sun, H., Qiao, J., Zhu, L., Zhang, F., Zhang, J., Tang, Z., Wei, X., Yang, J., Yuan, Q., Wang, W., Yang, X., Chu, H., Wang, Q., You, C., Ma, H., Sun, Y., Li, Y., Li, C., \& Ma, Y. (2021). Cell-free chemoenzymatic starch synthesis from carbon dioxide. Science, 373(6562), 1523-1527. https://doi.org/10.1126/science. abh4049

2. Nocera, D. G. (2009). Living healthy on a dying planet. Chemical Society Reviews, 38(1), 13-15. https://doi.org/10.1039/B820660K

3. Jiang, Z., Xiao, T., Kuznetsov, V. L., \& Edwards, P. P. (2010). Turning carbon dioxide into fuel. Philosophical Transactions of the Royal Society A: Mathematical, Physical and Engineering Sciences, 368(1923), 3343-3364. https://doi.org/10.1098/rsta.2010. 0119

4. Armaroli, N., \& Balzani, V. (2007). The future of energy supply: Challenges and opportunities. Angewandte Chemie International Edition, 46(1-2), 52-66. https://doi.org/10.1002/anie.200602373

5. de Tacconi, N. R., Lezna, R. O., Konduri, R., Ongeri, F., Rajeshwar, K., \& MacDonnell, F. M. (2005). Influence of $\mathrm{pH}$ on the photochemical and electrochemical reduction of the dinuclear ruthenium complex, [(phen) $2 \mathrm{Ru}$ (tatpp) $\mathrm{Ru}$ (phen) 2 ]Cl 4, in water: Proton-coupled sequential and concerted multi-electron reduction. Chemistry—A European Journal, 11(15), 4327-4339. https://doi.org/10.1002/chem.200401287

6. Singh, S., de Tacconi, N. R., Diaz, N. R. G., Lezna, R. O., Muñoz Zuñiga, J., Abayan, K., \& MacDonnell, F. M. (2011).
Photochemical two-electron reduction of a dinuclear ruthenium complex containing a bent tetraazatetrapyridopentacene bridging ligand: Pushing up the LUMO for storing more energy. Inorganic Chemistry, 50(19), 9318-9328. https://doi.org/10.1021/ic2006698

7. Paw, W., Connick, W. B., \& Eisenberg, R. (1998). Dipyridocatecholate-bridged complexes of platinum and ruthenium diimine chromophores. Inorganic Chemistry, 37(16), 3919-3926. https:// doi.org/10.1021/ic971447k

8. Lehn, J.-M., \& Ziessel, R. (1982). Photochemical generation of carbon monoxide and hydrogen by reduction of carbon dioxide and water under visible light irradiation. Proceedings of the National Academy of Sciences of the United States of America, 79(2), 701-704.

9. Koppenol, W. H., \& Rush, J. D. (1987). Reduction potential of the carbon dioxide/carbon dioxide radical anion: A comparison with other C1 radicals. The Journal of Physical Chemistry, 91(16), 4429-4430. https://doi.org/10.1021/j100300a045

10. Pradier, J. P., \& Pradier, C. M. (2014). Carbon dioxide chemistry: Environmental issues. Elsevier Science.

11. Schuchmann, K., \& Müller, V. (2014). Autotrophy at the thermodynamic limit of life: A model for energy conservation in acetogenic bacteria. Nature Reviews Microbiology, 12(12), 809-821. https://doi.org/10.1038/nrmicro3365

12. Shkrob, I. A., Marin, T. W., He, H., \& Zapol, P. (2012). Photoredox reactions and the catalytic cycle for carbon dioxide fixation and methanogenesis on metal oxides. The Journal of Physical Chemistry C, 116(17), 9450-9460. https://doi.org/10.1021/jp300 $122 \mathrm{v}$

13. Sleep, N. H., Meibom, A., Fridriksson, Th., Coleman, R. G., \& Bird, D. K. (2004). H2-rich fluids from serpentinization: Geochemical and biotic implications. Proceedings of the National Academy of Sciences, 101(35), 12818-12823. https://doi.org/10. 1073/pnas.0405289101

14. Scott, H. P., Hemley, R. J., Mao, H.-k, Herschbach, D. R., Fried, L. E., Howard, W. M., \& Bastea, S. (2004). Generation of methane in the Earth's mantle: In situ high pressure-temperature measurements of carbonate reduction. Proceedings of the National Academy of Sciences, 101(39), 14023-14026. https://doi.org/10.1073/ pnas.0405930101

15. Shively, J. M., van Keulen, G., \& Meijer, W. G. (1998). SOMETHING FROM ALMOST NOTHING: Carbon dioxide fixation in chemoautotrophs. Annual Review of Microbiology, 52(1), 191-230. https://doi.org/10.1146/annurev.micro.52.1.191

16. Varma, S. J., Muchowska, K. B., Chatelain, P., \& Moran, J. (2018). Native iron reduces CO2 to intermediates and end-products of the acetyl-CoA pathway. Nature Ecology \& Evolution, 2(6), 1019-1024. https://doi.org/10.1038/s41559-018-0542-2

17. Muchowska, K. B., Varma, S. J., Chevallot-Beroux, E., LethuillierKarl, L., Li, G., \& Moran, J. (2017). Metals promote sequences of the reverse Krebs cycle. Nature Ecology \& Evolution, 1(11), 1716-1721. https://doi.org/10.1038/s41559-017-0311-7

18. Muchowska, K. B., Varma, S. J., \& Moran, J. (2019). Synthesis and breakdown of universal metabolic precursors promoted by iron. Nature, 569(7754), 104-107. https://doi.org/10.1038/ s41586-019-1151-1

19. Keller, M. A., Kampjut, D., Harrison, S. A., \& Ralser, M. (2017). Sulfate radicals enable a non-enzymatic Krebs cycle precursor. Nature Ecology \& Evolution, 1(4), 1-9. https://doi.org/10.1038/ s41559-017-0083

20. Rosing, M. T. (2005). Thermodynamics of life on the planetary scale. International Journal of Astrobiology, 4(1), 9-11. https:// doi.org/10.1017/S147355040500248X

21. Khan, A. A., \& Tahir, M. (2019). Recent advancements in engineering approach towards design of photo-reactors for selective photocatalytic $\mathrm{CO} 2$ reduction to renewable fuels. Journal of $\mathrm{CO} 2$ 
Utilization, 29, 205-239. https://doi.org/10.1016/j.jcou.2018.12. 008

22. Hernández-Alonso, M. D., Fresno, F., Suárez, S., \& Coronado, J. M. (2009). Development of alternative photocatalysts to TiO2: Challenges and opportunities. Energy \& Environmental Science, 2(12), 1231. https://doi.org/10.1039/b907933e

23. Kim, I., \& Svendsen, H. F. (2007). Heat of absorption of carbon dioxide (CO 2) in Monoethanolamine (MEA) and 2-(Aminoethyl) ethanolamine (AEEA) solutions. Industrial \& Engineering Chemistry Research, 46(17), 5803-5809. https://doi.org/10.1021/ie061 6489

24. Liao, Y., Cao, S. W., Yuan, Y., Gu, Q., Zhang, Z., \& Xue, C. (2014). Efficient CO2 capture and photoreduction by aminefunctionalized TiO2. Chemistry-A European Journal, 20(33), 10220-10222. https://doi.org/10.1002/chem.201403321

25. Ishida, N., Shimamoto, Y., \& Murakami, M. (2012). Solar-driven incorporation of carbon dioxide into $\alpha$-amino ketones. Angewandte Chemie - International Edition, 51(47), 11750-11752. https://doi.org/10.1002/anie.201206166

26. Ju, T., Fu, Q., Ye, J., Zhang, Z., Liao, L., Yan, S., Tian, X., Luo, S., Li, J., \& Yu, D. (2018). Selective and catalytic hydrocarboxylation of enamides and imines with $\mathrm{CO}_{2}$ to generate $\alpha, \alpha$-disubstituted $\alpha$-amino acids. Angewandte Chemie International Edition, 57(42), 13897-13901. https://doi.org/10.1002/anie.201806874

27. Deamer, D. W. (1992). Polycyclic aromatic hydrocarbons: Primitive pigment systems in the prebiotic environment. Advances in Space Research, 12(4), 183-189. https://doi.org/10.1016/02731177(92)90171-S

28. Gui, Y. Y., Zhou, W. J., Ye, J. H., \& Yu, D. G. (2017). Photochemical carboxylation of activated $\mathrm{C}(\mathrm{sp} 3)-\mathrm{H}$ bonds with $\mathrm{CO} 2$. Chemsuschem, 10(7), 1337-1340. https://doi.org/10.1002/cssc. 201700205

29. Masuda, Y., Ishida, N., \& Murakami, M. (2015). Light-Driven carboxylation of $o$-Alkylphenyl ketones with $\mathrm{CO}_{2}$. Journal of the American Chemical Society, 137(44), 14063-14066. https:// doi.org/10.1021/jacs.5b10032

30. Matsuoka, S., Kohzuki, T., Pac, C., Ishida, A., Takamuku, S., Kusaba, M., Nakashima, N., \& Yanagida, S. (1992). Photocatalysis of oligo(p-phenylenes): Photochemical reduction of carbon dioxide with triethylamine. The Journal of Physical Chemistry, 96(11), 4437-4442. https://doi.org/10.1021/j100190a057

31. Seo, H., Katcher, M. H., \& Jamison, T. F. (2017). Photoredox activation of carbon dioxide for amino acid synthesis in continuous flow. Nature Chemistry, 9(5), 453-456. https://doi.org/10. 1038/nchem.2690

32. Keefe, A. D., \& Miller, S. L. (1996). Was ferrocyanide a prebiotic reagent? Origins of Life and Evolution of the Biosphere, 26(2), 111-129. https://doi.org/10.1007/BF01809851

33. Sharma, B. K., Ameta, R., Kaur, J., \& Ameta, S. C. (1997). Photocatalytic reduction of carbon dioxide over ferrocyanidecoated titanium dioxide powder. International Journal of Energy Research, 21(10), 923-929. https://doi.org/10.1002/ (SICI)1099-114X(199708)21:10\%3c923::AID-ER299\%3e3.0. $\mathrm{CO} ; 2-\mathrm{B}$

34. Hodgson, G. W., \& Ponnamperuma, C. (1968). Prebiotic porphyrin genesis: Porphyrins from electric discharge in methane, ammonia, and water vapor. Proceedings of the National Academy of Sciences, 59(1), 22-28. https://doi.org/10.1073/pnas.59.1.22

35. Masinovský, Z., Lozovaya, G. I., Sivash, A. A., \& Drašner, M. (1989). Porphyrin-proteinoid complexes as models of prebiotic photosensitizers. Bio Systems, 22(4), 305-310. https://doi.org/10. 1016/0303-2647(89)90052-X

36. Aylward, N., \& Bofinger, N. (2005). Possible origin for porphin derivatives in prebiotic chemistry-A computational study. Origins of Life and Evolution of Biospheres, 35(4), 345-368. https:// doi.org/10.1007/s11084-005-2044-x
37. Pleyer, H. L., Strasdeit, H., \& Fox, S. (2018). A possible prebiotic ancestry of porphyrin-type protein cofactors. Origins of Life and Evolution of Biospheres, 48(4), 347-371. https://doi.org/10.1007/ s11084-018-9567-4

38. Goncharova, N. V., \& Goldfeld, M. G. (1990). Magnesium porphyrins as possible photosensitizers of macroergic phosphate bonds formation during prebiotic evolution. Origins of Life and Evolution of the Biosphere, 20(3-4), 309-319. https://doi.org/10. 1007/BF01808113

39. Soares, A. R. M., Taniguchi, M., Chandrashaker, V., \& Lindsey, J. S. (2013). Expanded combinatorial formation of porphyrin macrocycles in aqueous solution containing vesicles. A prebiotic model. New Journal of Chemistry, 37(4), 1073. https://doi.org/10.1039/ c3nj41041b

40. Alexy, E. J., Hintz, C. W., Hughes, H. M., Taniguchi, M., \& Lindsey, J. S. (2015). Paley's watchmaker analogy and prebiotic synthetic chemistry in surfactant assemblies. Formaldehyde scavenging by pyrroles leading to porphyrins as a case study. Organic \& Biomolecular Chemistry, 13(39), 10025-10031. https://doi.org/ 10.1039/C5OB01409C

41. Grodkowski, J., Behar, D., Neta, P., \& Hambright, P. (1997). Iron porphyrin-catalyzed reduction of $\mathrm{CO} 2$. Photochemical and radiation chemical studies. Journal of Physical Chemistry A, 101(3), 248-254. https://doi.org/10.1021/jp9628139

42. Bonin, J., Chaussemier, M., Robert, M., \& Routier, M. (2014). Homogeneous photocatalytic reduction of $\mathrm{CO} 2$ to $\mathrm{CO}$ using iron $(0)$ porphyrin catalysts: Mechanism and intrinsic limitations. ChemCatChem, 6(11), 3200-3207. https://doi.org/10.1002/cctc. 201402515

43. Gotico, P., Halime, Z., \& Aukauloo, A. (2020). Recent advances in metalloporphyrin-based catalyst design towards carbon dioxide reduction: From bio-inspired second coordination sphere modifications to hierarchical architectures. Dalton Transactions, 49(8), 2381-2396. https://doi.org/10.1039/C9DT04709C

44. Margarit, C. G., Schnedermann, C., Asimow, N. G., \& Nocera, D. G. (2019). Carbon dioxide reduction by iron Hangman porphyrins. Organometallics, 38(6), 1219-1223. https://doi.org/10. 1021/acs.organomet.8b00334

45. Masciocchi, N., Bruni, S., Cariati, E., Cariati, F., Galli, S., \& Sironi, A. (2001). Extended polymorphism in Copper(II) imidazolate polymers: A spectroscopic and XRPD structural study. Inorganic Chemistry, 40(23), 5897-5905. https://doi.org/10. 1021/ic010384+

46. Li, J., Luo, D., Yang, C., He, S., Chen, S., Lin, J., Zhu, L., \& $\mathrm{Li}, \mathrm{X}$. (2013). Copper(II) imidazolate frameworks as highly efficient photocatalysts for reduction of $\mathrm{CO} 2$ into methanol under visible light irradiation. Journal of Solid State Chemistry, 203, 154-159. https://doi.org/10.1016/j.jssc.2013.04.016

47. Roy, S. C., Varghese, O. K., Paulose, M., \& Grimes, C. A. (2010). Toward solar fuels: Photocatalytic conversion of carbon dioxide to hydrocarbons. ACS Nano, 4(3), 1259-1278. https:// doi.org/10.1021/nn9015423

48. Zhang, Z., Li, A., Cao, S.-W., Bosman, M., Li, S., \& Xue, C. (2014). Direct evidence of plasmon enhancement on photocatalytic hydrogen generation over $\mathrm{Au} / \mathrm{Pt}$-decorated $\mathrm{TiO}_{2}$ nanofibers. Nanoscale, 6(10), 5217-5222. https://doi.org/10.1039/ C3NR06562F

49. Hoffmann, M. R., Martin, S. T., Choi, W., \& Bahnemann, D. W. (1995). Environmental applications of semiconductor photocatalysis. Chemical Reviews, 95(1), 69-96. https://doi.org/10. 1021/cr00033a004

50. Yuan, Y.-P., Ruan, L.-W., Barber, J., Joachim Loo, S. C., \& Xue, C. (2014). Hetero-nanostructured suspended photocatalysts for solar-to-fuel conversion. Energy \& Environmental Science, 7(12), 3934-3951. https://doi.org/10.1039/C4EE02914C 
51. Huang, Y., Yan, C.-F., Guo, C.-Q., \& Huang, S.-L. (2015). Enhanced photoreduction activity of carbon dioxide over $\mathrm{Co}_{3} \mathrm{O}_{4} / \mathrm{CeO}_{2}$ catalysts under visible light irradiation. International Journal of Photoenergy, 2015, 1-11. https://doi.org/10. $1155 / 2015 / 230808$

52. Hu, S., Zhou, F., Wang, L., \& Zhang, J. (2011). Preparation of $\mathrm{Cu} 2 \mathrm{O} / \mathrm{CeO} 2$ heterojunction photocatalyst for the degradation of Acid Orange 7 under visible light irradiation. Catalysis Communications, 12(9), 794-797. https://doi.org/10.1016/j.catcom. 2011.01.027

53. Wang, J. C., Zhang, L., Fang, W. X., Ren, J., Li, Y. Y., Yao, H. C., Wang, J. S., \& Li, Z. J. (2015). Enhanced photoreduction $\mathrm{CO} 2$ activity over direct $\mathrm{Z}$-Scheme $\alpha-\mathrm{Fe} 2 \mathrm{O} 3 / \mathrm{Cu} 2 \mathrm{O}$ heterostructures under visible light irradiation. ACS Applied Materials and Interfaces, 7(16), 8631-8639. https://doi.org/10.1021/acsami. $5 \mathrm{~b} 00822$

54. Roldan, A., Hollingsworth, N., Roffey, A., Islam, H. U., Goodall, J. B. M., Catlow, C. R. A., Darr, J. A., Bras, W., Sankar, G., Holt, K. B., Hogarth, G., \& De Leeuw, N. H. (2015). Bio-inspired $\mathrm{CO} 2$ conversion by iron sulfide catalysts under sustainable conditions. Chemical Communications, 51(35), 7501-7504. https://doi.org/10.1039/c5cc02078f

55. Tetzlaff, D., Simon, C., Achilleos, D. S., Smialkowski, M., Junge Puring, K., Bloesser, A., Piontek, S., Kasap, H., Siegmund, D., Reisner, E., Marschall, R., \& Apfel, U.-P. (2019). Fe $\mathrm{x}$ Ni 9-x S $8(\mathrm{x}=3-6)$ as potential photocatalysts for solardriven hydrogen production? Faraday Discussions, 215, 216226. https://doi.org/10.1039/C8FD00173A

56. Egel, R. (2014). Origins and emergent evolution of life: The colloid microsphere hypothesis revisited. Origins of Life and Evolution of Biospheres, 44(2), 87-110. https://doi.org/10.1007/ s11084-014-9363-8

57. Zhou, R., \& Guzman, M. I. (2014). $\mathrm{CO}_{2}$ Reduction under periodic illumination of ZnS. The Journal of Physical Chemistry C, 118(22), 11649-11656. https://doi.org/10.1021/jp4126039

58. Zhang, X. V., Martin, S. T., Friend, C. M., Schoonen, M. A. A., \& Holland, H. D. (2004). Mineral-assisted pathways in prebiotic synthesis: Photoelectrochemical reduction of Carbon(+IV) by manganese sulfide. Journal of the American Chemical Society, 126(36), 11247-11253. https://doi.org/10.1021/ja0476415

59. Chen, Y., Chen, K., Fu, J., Yamaguchi, A., Li, H., Pan, H., Hu, J., Miyauchi, M., \& Liu, M. (2020). Recent advances in the utilization of copper sulfide compounds for electrochemical $\mathrm{CO} 2$ reduction. Nano Materials Science, 2(3), 235-247. https://doi.org/10. 1016/j.nanoms.2019.10.006

60. Ma, W., Xie, S., Zhang, X.-G., Sun, F., Kang, J., Jiang, Z., Zhang, Q., Wu, D.-Y., \& Wang, Y. (2019). Promoting electrocatalytic $\mathrm{CO} 2$ reduction to formate via sulfur-boosting water activation on indium surfaces. Nature Communications, 10(1), 892. https://doi. org/10.1038/s41467-019-08805-X

61. Li, Y., Li, Y., Liu, Y., Wu, Y., Wu, J., Wang, B., Ye, H., Jia, H., Wang, X., Li, L., Zhu, M., Ding, H., Lai, Y., Wang, C., Dick, J., \& Lu, A. (2020). Photoreduction of inorganic carbon(+IV) by elemental sulfur: Implications for prebiotic synthesis in terrestrial hot springs. Science Advances. https://doi.org/10.1126/ sciadv.abc3687

62. Kim, R., Kim, J., Do, J. Y., Seo, M. W., \& Kang, M. (2019). Carbon dioxide photoreduction on the Bi2S3/MoS2 catalyst. Catalysts, 9(12), 1-19. https://doi.org/10.3390/catal9120998

63. Kanemoto, M., Shiragami, T., Pac, C., \& Yanagida, S. (1992). Semiconductor photocatalysis. Effective photoreduction of carbon dioxide catalyzed by $\mathrm{ZnS}$ quantum crystallites with low density of surface defects. Journal of Physical Chemistry, 96(8), 3521-3526. https://doi.org/10.1021/j100187a062

64. Eggins, B. R., Robertson, P. K. J., Stewart, J. H., \& Woods, E. (1993). Photoreduction of carbon dioxide on zinc sulfide to give four-carbon and two-carbon acids. Journal of the Chemical Society, Chemical Communications, 4, 349. https://doi.org/10.1039/ c39930000349

65. Pan, H., \& Heagy, M. D. (2020). Photons to formate-A review on photocatalytic reduction of $\mathrm{CO} 2$ to formic acid. Nanomaterials, 10(12), 1-24. https://doi.org/10.3390/nano10122422

66. Arai, T., Tajima, S., Sato, S., Uemura, K., Morikawa, T., \& Kajino, T. (2011). Selective CO2 conversion to formate in water using a CZTS photocathode modified with a ruthenium complex polymer. Chemical Communications, 47(47), 12664. https://doi. org/10.1039/c1cc16160a

67. Liu, B.-J., Torimoto, T., \& Yoneyama, H. (1998). Photocatalytic reduction of $\mathrm{CO} 2$ using surface-modified CdS photocatalysts in organic solvents. Journal of Photochemistry and Photobiology A: Chemistry, 113(1), 93-97. https://doi.org/10.1016/S10106030(97)00318-3

68. Shi, J., Shao, D., Zhang, J., Tan, D., Tan, X., Zhang, B., Han, B., Zhang, F., Liu, L., \& Cheng, X. (2018). Highly selective and efficient reduction of $\mathrm{CO}_{2}$ to $\mathrm{CO}$ on cadmium electrodes derived from cadmium hydroxide. Chemical Communications, 54(43), 5450-5453. https://doi.org/10.1039/C8CC02055H

69. Cody, G. D. (2004). Transition metal sulfides and the origins of metabolism. Annual Review of Earth and Planetary Sciences, 32(1), 569-599. https://doi.org/10.1146/annurev.earth.32.101802. 120225

70. Farooq, U., Phul, R., Alshehri, S. M., Ahmed, J., \& Ahmad, T. (2019). Electrocatalytic and enhanced photocatalytic applications of sodium niobate nanoparticles developed by citrate precursor route. Scientific Reports, 9(1), 4488. https://doi.org/10.1038/ s41598-019-40745-w

71. Qian, W., Xu, S., Zhang, X., Li, C., Yang, W., Bowen, C. R., \& Yang, Y. (2021). Differences and similarities of photocatalysis and electrocatalysis in two-dimensional nanomaterials: Strategies, traps applications and challenges. Nano-Micro Letters, 13(1), 156. https://doi.org/10.1007/s40820-021-00681-9

72. Li, Y., Kitadai, N., \& Nakamura, R. (2018). Chemical diversity of metal sulfide minerals and its implications for the origin of life. Life, 8(4), 46. https://doi.org/10.3390/life8040046

73. Khan, F. S., Sugiyama, M., Fujii, K., Tver'yanovich, Y. S., \& Nakano, Y. (2020). Electrochemical reduction of CO2 using Germanium-Sulfide-Indium amorphous glass structures. Heliyon, 6(4), e03513. https://doi.org/10.1016/j.heliyon.2020.e03513

74. Orgel, L. E. (2008). The implausibility of metabolic cycles on the prebiotic earth. PLoS Biology, 6(1), e18. https://doi.org/10.1371/ journal.pbio.0060018

75. Trail, D., Watson, E. B., \& Tailby, N. D. (2011). The oxidation state of Hadean magmas and implications for early Earth's atmosphere. Nature, 480(7375), 79-82. https://doi.org/10.1038/natur e10655

76. Kawai, J., McLendon, D. C., Kim, H.-J., \& Benner, S. A. (2019). Hydroxymethanesulfonate from volcanic sulfur dioxide: A "Mineral" reservoir for formaldehyde and other simple carbohydrates in prebiotic chemistry. Astrobiology, 19(4), 506-516. https://doi. org/10.1089/ast.2017.1800

77. Hayon, E., Treinin, A., \& Wilf, J. (1972). Electronic spectra, photochemistry, and autoxidation mechanism of the sulfite-bisulfitepyrosulfite systems. SO2-, SO3-, SO4-, and SO5- radicals. Journal of the American Chemical Society, 94(1), 47-57. https://doi. org/10.1021/ja00756a009

78. Schindewolf, U. (1968). Formation and properties of solvated electrons. Angewandte Chemie International Edition in English, 7(3), 190-203. https://doi.org/10.1002/anie.196801901

79. Das, T. N., Huie, R. E., \& Neta, P. (1999). Reduction potentials of SO $3 \bullet-$, SO $5 \bullet-$, and S 4 O $6 \bullet 3$ - radicals in aqueous solution. The Journal of Physical Chemistry A, 103(18), 3581-3588. https://doi.org/10.1021/jp9900234 
80. Janik, I., \& Tripathi, G. N. R. (2016). The nature of the CO2radical anion in water. The Journal of Chemical Physics, 144(15), 154307. https://doi.org/10.1063/1.4946868

81. Balaj, O. P., Siu, C.-K., Balteanu, I., Beyer, M. K., \& Bondybey, V. E. (2004). Reactions of hydrated electrons $\left(\mathrm{H}_{2} \mathrm{O}\right) \mathrm{n}^{-}$with carbon dioxide and molecular oxygen: Hydration of the $\mathrm{CO}_{2}-$ and $\mathrm{O}_{2}$ - ions. Chemistry - A European Journal, 10(19), 4822-4830. https://doi.org/10.1002/chem.200400416

82. Roughton, F. J. W., \& Booth, V. H. (1938). The catalytic effect of buffers on the reaction $\mathrm{CO} 2+\mathrm{H} 2 \mathrm{O} \rightleftharpoons \mathrm{H} 2 \mathrm{CO} 3$. Biochemical Journal, 32(11), 2049-2069. https://doi.org/10.1042/bj0322049
83. Liu, Z., Wu, L.-F., Kufner, C. L., Sasselov, D. D., Fischer, W. W., \& Sutherland, J. D. (2021). Prebiotic photoredox synthesis from carbon dioxide and sulfite. Nature Chemistry, 13(11), 1126-1132. https://doi.org/10.1038/s41557-021-00789-w

84. Ritson, D. J., Battilocchio, C., Ley, S. V., \& Sutherland, J. D. (2018). Mimicking the surface and prebiotic chemistry of early Earth using flow chemistry. Nature Communications, 9(1), 1821. https://doi.org/10.1038/s41467-018-04147-2

85. NaiduSagi, V., Karri, P., Hu, F., \& Krishnamurthy, R. (2011). Diastereoselective self-condensation of dihydroxyfumaric acid in water: potential route to sugars. Angewandte Chemie International Edition, 50(35), 8127-8130. https://doi.org/10.1002/anie.20110 2045 